\author{
Marquette University \\ e-Publications@Marquette
}

Civil and Environmental Engineering Faculty Research and Publications
Civil and Environmental Engineering,

Department of

3-12-2019

\title{
Adsorption of Organic Micropollutants Onto Biochar: A Review of Relevant Kinetics, Mechanisms and Equilibrium
}

\author{
Yiran Tong \\ Marquette University \\ Patrick J. McNamara \\ Marquette University, patrick.mcnamara@marquette.edu \\ Brooke K. Mayer \\ Marquette University, Brooke.Mayer@marquette.edu
}

Follow this and additional works at: https://epublications.marquette.edu/civengin_fac

Part of the Civil Engineering Commons

\section{Recommended Citation}

Tong, Yiran; McNamara, Patrick J.; and Mayer, Brooke K., "Adsorption of Organic Micropollutants Onto Biochar: A Review of Relevant Kinetics, Mechanisms and Equilibrium" (2019). Civil and Environmental Engineering Faculty Research and Publications. 237.

https://epublications.marquette.edu/civengin_fac/237 
Marquette University

e-Publications@Marquette

\title{
Civil, Construction and Environmental Engineering Faculty Research and Publications/College of Engineering
}

This paper is NOT THE PUBLISHED VERSION; but the author's final, peer-reviewed manuscript. The published version may be accessed by following the link in the citation below.

Environmental Science : Water Research and Technology, Vol. 5 (2019): 821-838. DOI. This article is (C) Royal Society of Chemistry and permission has been granted for this version to appear in $\underline{\mathrm{e}-}$ Publications@Marquette. Royal Society of Chemistry does not grant permission for this article to be further copied/distributed or hosted elsewhere without the express permission from Royal Society of Chemistry.

\section{Adsorption of Organic Micropollutants Onto Biochar: A Review of Relevant Kinetics, Mechanisms and Equilibrium}

\author{
Yiran Tong \\ Department of Civil, Construction and Environmental Engineering, Marquette University, Milwaukee, WI \\ Patrick J. McNamara \\ Department of Civil, Construction and Environmental Engineering, Marquette University, Milwaukee, WI \\ Brooke K. Mayer \\ Department of Civil, Construction and Environmental Engineering, Marquette University, Milwaukee, WI
}




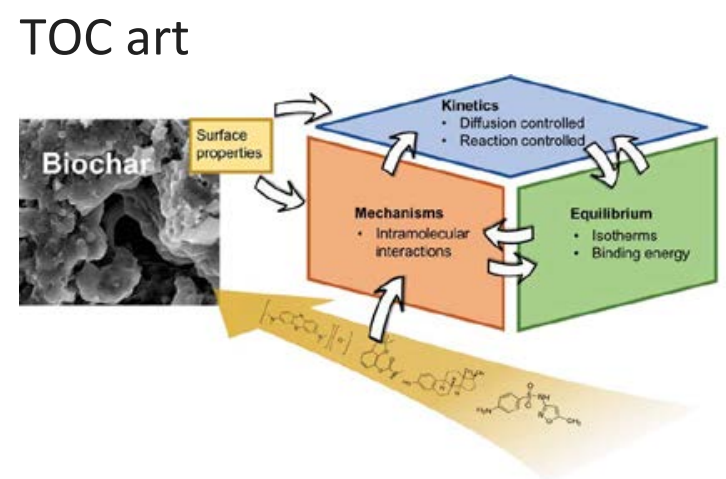

\section{Abstract}

As an alternative to activated carbon, biochar has been considered for removal of organic micropollutants from water and wastewater via adsorption. This review elaborates on the fundamental basis of adsorption kinetics, mechanisms, and equilibrium with respect to biochar-based adsorption of micropollutants. The objectives include: 1) linking biochar surface properties with adsorption abilities, 2) categorizing the kinetics of adsorption of aqueous-phase organic compounds onto biochar, 3) categorizing the molecular-scale interactions between organic micropollutants and biochar, and 4) reviewing existing quantitative methods for characterizing adsorption equilibrium of organic micropollutants from water onto an adsorbent surface. To fulfill these goals, the relationships among biochar surface properties, adsorption kinetics, mechanisms, and equilibrium were clarified as current literature often lacks such discussion or may include conflicting descriptions. Due to its heterogeneous nature, research on biochar's adsorption potential for micropollutants is ambiguous. By adapting adsorption theories to biochar application specifically, this review helps to inform future research in terms of addressing knowledge gaps in characterizing and improving biochar adsorption.

\section{Keywords}

Thermodynamics, sorption, emerging contaminants, wastewater; pyrolysis

\section{Nomenclature}

$Q$ mass loading of adsorbate on solids $(\mathrm{mg} / \mathrm{g}$ )

$\mathrm{Q}_{\mathrm{e}}$ mass loading of adsorbate on solid at adsorption equilibrium $(\mathrm{mg} / \mathrm{g})$

J flux of adsorbate $(\mathrm{mg} / \mathrm{g} / \mathrm{min})$

$\mathrm{k}_{\mathrm{f}}$ film diffusion coefficient

A volumetric surface area of adsorbent $\left(\mathrm{m}^{2} / \mathrm{m}^{3}\right)$

$C$ adsorbate concentration in aqueous phase $(\mathrm{mg} / \mathrm{L})$

$\mathrm{C}_{\mathrm{e}}$ adsorbate concentration in aqueous phase at equilibrium $(\mathrm{mg} / \mathrm{L})$

$D_{s}$ effective surface diffusion coefficient $\left(\mathrm{mm}^{2} / \mathrm{s}\right)$

$\mathrm{k}_{1}, \mathrm{k}_{2}$ pseudo first-order $\left(\mathrm{sec}^{-1}\right)$ and second-order rate constants (L/mol/sec)

\subsection{Introduction}

The occurrence of organic micropollutants in the environment is typically associated with increasing population and anthropogenic activities ${ }^{1}$. Municipal water resource recovery facilities (WRRFs) are a major source of 
organic micropollutant loading to aquatic environments ${ }^{1}$. An estimated 300 million tons per year of micropollutants, including synthetic industrial chemicals, pharmaceuticals, flame retardants, artificial sweeteners, and hormones enter natural waters via wastewater discharges ${ }^{1-3}$. Micropollutants are of concern because they elicit biological and ecological impacts at very low concentrations (ng/L to $\mu \mathrm{g} / \mathrm{L})^{4-6}$. Micropollutants do not necessarily result in acute toxicity; instead, they are suspected to have long-term effects on organisms chronically exposed to these compounds 7,8 .

As WRRFs process the majority of wastewater stemming from anthropogenic activities, they are a major collection and release point of organic micropollutants ${ }^{3}$. The fate of 51 micropollutants during wastewater treatment is highly variable, as they can be discharged with the liquid effluent, [bio]degraded, volatilized, or retained on solid surfaces via adsorption, e.g., adsorption to suspended solids, sludge particles, or filter media 9,10 . The adsorptive behavior of organic micropollutants onto solids in engineered and natural environments substantially affects the fate and removal of micropollutants that are not amenable to biodegradation ${ }^{11}$.

Removal of micropollutants from the aqueous phase during tertiary polishing at WRRFs is commonly achieved using treatment technologies such as adsorption by porous carbonaceous materials. For example, activated carbon can remove carbamazepine, 17B-estradiol, and sulfamethoxazole via adsorption ${ }^{12,13}$. Biochar is another type of carbonaceous solid material, and is produced by pyrolyzing (thermo-conversion under anoxic conditions) carbon-based feedstock. To volatilize tars, the lower range of pyrolysis temperature is typically $400^{\circ} \mathrm{C}$ 14-16. Pyrolysis can produce multiple value-added products such as py-gas, which can potentially offset energy costs for pyrolysis 17,18, and biochar, which can be used as a soil amendment and adsorbent 16,19,20. Compared to widely-adopted activated carbon, research on biochar as an adsorbent to remove micropollutants is still in the early stages; however, biochar's potential for this application is attracting greater attention 21 . Studies have tested the feasibility of using biochar derived from biosolids, plant residuals, and animal manure to adsorb hormones, pharmaceuticals, and pesticides $10,20,22,23$. For example, up to $60 \%$ adsorption of endocrine disrupting compounds such as bisphenol A, atrazine, $17 \alpha$-ethinylestradiol ${ }^{10}$, and triazine herbicides 24 was observedusing plant-derived biochar.

Unlike activated carbon, biochar is produced from more diverse feedstocks under less energy-intensive thermal conditions. Additionally, chemical activation of the feedstock and gas activation during thermal conversion are required for producing activated carbon, but they are usually not necessary for producing biochar 25,26 . Biochar's unique properties stem from these factors. For example, biochar's surface area and mechanical hardness tend to be lower than activated carbon due to production under less energy-intensive thermal conditions and lack of activation. In spite of the differences, biochar and activated carbon share commonalities in terms of adsorption functionality, e.g., adsorption via $\pi$ - $\pi$ electron-donor-acceptor interactions primarily relies on the polycyclic aromatic network of the charcoals 27 . Accordingly, the fundamental basis for adsorption, as described in detail in literature focused on porous adsorbents including activated carbon, is adaptable to biochar with adjustments in terms of biochar's properties.

To design and optimize WRRF adsorption treatment processes targeting removal of micropollutants using biochar, the adsorptive behavior of micropollutants onto biochar must be established. The influence of biochar surface properties on micropollutant removal is an important consideration for process improvement. 
Additionally, adsorption kinetics, mechanisms, and equilibrium are needed to characterize adsorption of micropollutants from wastewater onto biochar. In the case of aqueous-phase adsorption, kinetics define the diffusion or reaction rate, reflecting how quickly adsorption occurs. Adsorption mechanisms indicate the type of intermolecular interactions at play, which depend on the physicochemical properties of the adsorbent and the adsorbate as well as the bulk solution. Adsorption equilibrium between the solid- and aqueous-phases can be described using isotherms and thermodynamic parameters.

Adsorption kinetics, mechanisms, and equilibrium are not independent, but relate to one another, making it important to understand these relationships and their relevance to micropollutant removal efficiency using biochar. However, previous reviews of aqueous-phase adsorption on biochar have not clearly and consistently described these relationships ${ }^{28-32}$. Thus, this tutorial review focuses on correlations among the adsorption concepts of adsorbent surface properties, kinetics, adsorption mechanisms, and equilibrium, in the specific context of biochar. Equilibrium isotherms provide the boundary conditions needed to solve the diffusion rate equations characterizing kinetics 33,34 . Equilibrium isotherms are also used to extrapolate thermodynamic parameters ${ }^{35-37}$. Thermodynamic parameters such as the magnitude of enthalpy change of adsorption provide good indicators of intermolecular interactions. For example, the enthalpy change of chemical adsorption involving formation of covalent bonds is on the order of $>100 \mathrm{~kJ} / \mathrm{mol}$, while smaller changes in enthalpy usually indicate weak physical adsorption 38,39 . The contribution of adsorption mechanisms to total free energy change is useful in modifying adsorbent surface properties to improve removal of target contaminants. The rate-limiting step of adsorption kinetics relates to binding mechanisms as well. For physical adsorption, intramolecular diffusion is more likely the rate-limiting step, while for adsorption involving shared electron pairs via covalent or ionic bonds, reaction rate-limiting kinetic models, such as pseudo-first and pseudo-second order (PFO and PSO) are more appropriate 40 .

It follows that quantitative characterization of a batch adsorption system, such as kinetic and isotherm modeling, is essential to inform design of flow-through filter beds or column operation 41,42 . However, misunderstanding fundamental concepts of biochar surface properties and adsorption kinetics, mechanisms, and equilibrium can lead to inappropriate interpretation and application. Therefore, the goal of this tutorial review is to introduce and provide a clear overview of the linkages between biochar surface properties and adsorption potential as well as the theoretical basis and relationships among adsorption kinetics, mechanisms, and equilibrium. Specifically, this review focuses on clarifying adsorption between aqueous-phase organic micropollutants and solids materials, which can be applied to biochar adsorption. Critical analysis identifying knowledge gaps along with research needs to fill these gaps is also presented. Specific objectives include: 1 ) linking biochar surface properties with its adsorption abilities, 2) categorizing the kinetics of adsorption of aqueous-phase organic compounds onto biochar, 3) categorizing the molecular-scale interactions between organic micropollutants and biochar, and 4) reviewing existing quantitative methods for characterizing adsorption equilibrium of organic micropollutants from water onto an adsorbent surface.

\subsection{Impact of biochar surface properties on adsorption of organic}

\section{micropollutants}

The adsorption of organic micropollutants onto solid adsorbents is greatly affected by both the nature of the compounds-e.g., polar vs. non-polar and neutral molecules vs. dissociated ions-and the surface properties of the adsorbent. For instance, an adsorbent with smaller-sized mesopores can increase steric hindrance for molecules diffusing into adsorption sites deep in the pores 43 . Additionally, an adsorbent with a high ratio of 
non-polar organic carbon moieties can attract neutral hydrophobic molecules ${ }^{44}$. Accordingly, understanding adsorption kinetics and mechanisms requires knowledge of the adsorbent itself. In this section, biochar surface properties are discussed. Biochar surface properties depend on the characteristics of feedstock biomass, the pyrolysis process, and post-pyrolysis handling/treatment of biochar ${ }^{16,45}$

\subsection{Structure geometry and pore size distribution}

Unlike coals and cokes that contain crystalline particles composing graphite-like layers, biochar structure is amorphous ${ }^{45}$. Therefore, biochar can include different types of adsorption sites, and the site type distribution is usually heterogeneous. Biochar's carbon backbone structure often features slit-shaped pores or honeycomb structures 46,47 . Biochar pore sizes can range from sub-nanometer to tens of micrometers 45,48 , but a large portion of biochar pores are micropores $(<2 \mathrm{~nm})$ inside the pore network, while pores connecting to the biochar surface are mostly mesopores $(2 \mathrm{~nm}$ to $50 \mathrm{~nm}){ }^{24,49}$. Steric hindrance due to pore geometry occurs when the pore aperture is too narrow for adsorbate molecules to quickly diffuse into deeper micropore sites. This effect is important when the ratio of pore aperture to the minimum critical organic molecular diameter is below $10^{50}$. Xiao and Pignatello ${ }^{24}$ studied biochar-based adsorption of a series of triazines and found that the compounds' diffusion coefficients into the biochar pores followed the order pyridine>quinolone>prometon, which is the reverse order of the critical diameter. These results illustrated that steric hindrance affects triazine diffusion into deep tunnels. The free energies of triazines and benzene on the same biochar also suggested that the adsorption of the triazine is suppressed by $\sim 6.2 \mathrm{~kJ} / \mathrm{mol}$ compared to benzene due to steric effects 15324 .

\subsection{Surface charge}

Biochar's surface charge is an important property governing adsorption of ionic molecules via coulombic attraction. Biochar may bear electrical charge deficits due to dissociable functional groups such as $-\mathrm{OH},-\mathrm{H}$ and $\mathrm{COOH}$ in the biochar structure ${ }^{51}$. Surface charge can be measured using ion exchange capacity or zeta potential/isoelectric point. Ion exchange capacity for biochar is a term adapted from soil properties 52 , where cation exchange capacity (CEC) measures the negative charge of biochar for retaining cations, and vice-versa for anion exchange capacity (AEC). Zeta potential is more commonly used to quantify surface charge. Zeta potential is the electric potential at the hydrodynamic shear surface of a particle, and can be used to predict the coulombic interaction (repulsion or attraction) between the particle and ions 27 . Zeta potential is impacted by solution $\mathrm{pH}$ and ionic strength. The $\mathrm{pH}$ at which zeta potential is zero is called the isoelectric point (IEP). The IEP assesses a particle's external surface charge in a given solution, as assessed using zetasizer instrumentation, whereas another commonly reported parameter, the point of zero net charge (PZNC), represents the total net electrical double layer surface charge 51,53 .

Interactions between a charged surface and ions are likely affected by coulombic attraction. Both the surface charge of biochar and the extent of dissociation of organic pollutants as a function of $\mathrm{pH}$, as discussed in Section 4.1.2, should be considered when probing the role of coulombic interaction.

\subsection{Organic content of biochar}

Aromaticity and polarity are two common indicators of organic content in biochar. Aromaticity is the proportion of aromatic carbon content relative to total carbon content ${ }^{54}$. The aromaticity of biochar is influenced by feedstock and pyrolysis conditions. For example, using wood as the pyrolysis feedstock can promote aromaticity 
because of the inherently high amount of aromatic lignin inherent in wood ${ }^{55}$. As for the impact of pyrolysis conditions, high treatment temperatures are commonly reported for increasing biochar aromaticity. The hydrogen/carbon $(\mathrm{H} / \mathrm{C})$ index is used to indirectly represent the aromaticity-a low value indicates high organic carbon content and high aromaticity. As pyrolysis temperature increases, biochar's carbon content tends to increase, and aliphatic carbons become incorporated into aromatic rings through the loss of a hydrogen 56 . Chen et al. ${ }^{57}$ observed that $\mathrm{H} / \mathrm{C}$ values of pine needle biochar decreased from 1.44 to 0.18 as pyrolysis temperature increased from $100^{\circ} \mathrm{C}$ to $700^{\circ} \mathrm{C}$. Direct detection of aromatic structures in biochar can be conducted through nuclear magnetic resonance ${ }^{58}$. Negative correlations between biochar aromaticity and the Freundlich parameter $n$ were observed using biochar pyrolyzed at $100-700^{\circ} \mathrm{C}$ to adsorb organic contaminants 57,59 . The high aromaticity (approximately $78 \%$ aromatic carbon) and strong nonlinear adsorption (low $\mathrm{n}$ values, $<0.4)$ observed for plant biochars suggested that low molecular weight aromatic carbon may play a significant role in the overall adsorption of fluorinated herbicides 59 .

Polarity of carbonaceous adsorbents accounts for the aliphatic portion of the biochar and is also related to the adsorption of organic compounds 60 . The proportion of polar functional groups can be indirectly represented using the oxygen+nitrogen/carbon $((\mathrm{O}+\mathrm{N}) / \mathrm{C})$ index ${ }^{57}$. High levels of oxygen-containing functional groups, such as carboxyl groups, may increase biochar's overall polarity. In general, the polar moiety of biochar has a stronger adsorption affinity and higher capacity for polar and ionic organic compounds, and a lower affinity for hydrophobic compounds 60,61 . For instance, the adsorption capacity parameter, $\mathrm{K}$, of non-polar phenanthrene was inversely correlated with the polarity index of humic acid ${ }^{60}$. Lian et al. ${ }^{62}$ also found that adsorption of SMX increased for biochars produced at low temperatures with more polar functional groups. However, due to the complexity of biochar materials, the interactions of polar compounds with polar biochar moieties such as $\mathrm{O}$ containing groups are not always the driving force for adsorption 63 .

Due to incomplete carbonization using less intense thermal conversion compared to 204 activated carbon, biochar's organic content can be classified into carbonized and non-carbonized portions. Partitioning of organic compounds into the non-carbonized phase usually demonstrates strong linearity in isotherms, while adsorption on the carbonized fractions is characterized by isotherms with curvature ${ }^{64,65}$. Chen et al. ${ }^{57}$ observed transitional adsorption and partitioning for non-polar compounds on pine-needle biochar, finding that the partitioning phase evolves from an amorphous polar aliphatic domain to a condensed aromatic core with increasing pyrolytic temperature. Accordingly, the (non-) carbonized phases align with the aromaticity and polarity of biochar.

\subsection{Ash content of biochar}

Ash content, or the residual mass remaining after high temperature combustion, can account for $1-80 \%$ of total biochar weight 66,67 , depending on the feedstock. A larger proportion of ash occurs for biochar produced with mineral-rich feedstock such as industrial wastes, grass and wastewater biosolids ${ }^{16,66}$. Lower ash proportions are found in biochar derived from wood ${ }^{68}$. Temperature has less influence on ash content relative to the type of feedstock, with ash content varying by up to $10 \%$ as a function of temperature $66,68,69$. Biochar ash content is primarily associated with surface polarity and pore distribution ${ }^{66,69}$. Sun et al. ${ }^{69}$ observed asignificant positive correlation $(\mathrm{p}<0.01)$ between ash content and surface polarity as quantified by the ratio of $(\mathrm{N}+\mathrm{O}) / \mathrm{C}$. 
However, there was no apparent correlation with bulk polarity. After de-ashing, non-polar moieties such as aromatic groups tend to be more accessible for hydrophobic or $n$ interactions, which promotes adsorption of non-polar compounds such as phenathrene and atrazine 69,70 . Development of mesopores from micropores is also affected by ash content. High ash-content biochars such as sludge-derived biochar (73\%wt) and distillers dried grain-derived biochar (45\%wt) were found to have well developed mesopore structure 67,71 , facilitating adsorption of small organic molecules as there was less competition from large molecules such as dissolved organic matter 67 .

\subsection{Other dissociable functional groups}

Increases in other functional groups on biochar (e.g., $-\mathrm{COOH},-\mathrm{OH}$, and $-\mathrm{NH}$ 2) often relate to post-treatment steps used to condition biochar after pyrolysis. Post-pyrolysis modification of biochar differs from activation as the activation step used during activated carbon production is defined as the carbonization of feedstocks in the presence of chemical reagents ${ }^{72}$. Post-pyrolysis additions of $\mathrm{H}$-containing groups can serve as hydrogen donors to promote adsorption of organic compounds via formation of $\mathrm{H}$-bonds. Post-pyrolysis treatment using methanol under acidic conditions increased carboxyl content for rice-husk biochar, which enhanced adsorption of tetracycline ${ }^{73}$. Due to biochar's complexity, it is also possible for the biochar to retain organic hydroxyl groups such as alcohol or phenolic hydroxyl groups 74 .

Biochar preparation strongly influences the aforementioned properties, as summarized in Figure 1. Properties such as pore size, functional groups, aromaticity, polarity, and ash (mineral) content subsequently determine 1) whether or not kinetics are diffusion controlled; 2) the intermolecular forces involved in organic attachment (mechanism), which are determined by both organic molecules and biochar surface functional groups; and 3 ) equilibrium between two phases, which is characterized by isotherms and thermodynamic parameters such as enthalpy and free energy. As such, a full profile of organic adsorption versus biochar properties can theoretically be established. However, the complexity and heterogeneity of biochar is currently the biggest obstacle hindering research. Lattao et al. ${ }^{75}$ found no obvious simple correlation for adsorption capacity as a function of the extent of wood biochar carbonization, surface area, or porosity. The use of model materials accounting for only one aspect of biochar properties is a feasible approach to isolate a minimal number of factors that can affect adsorption. For example, graphene mimics fused aromatic rings 63 , and humic acid mimics non-carbonized phases 65 .

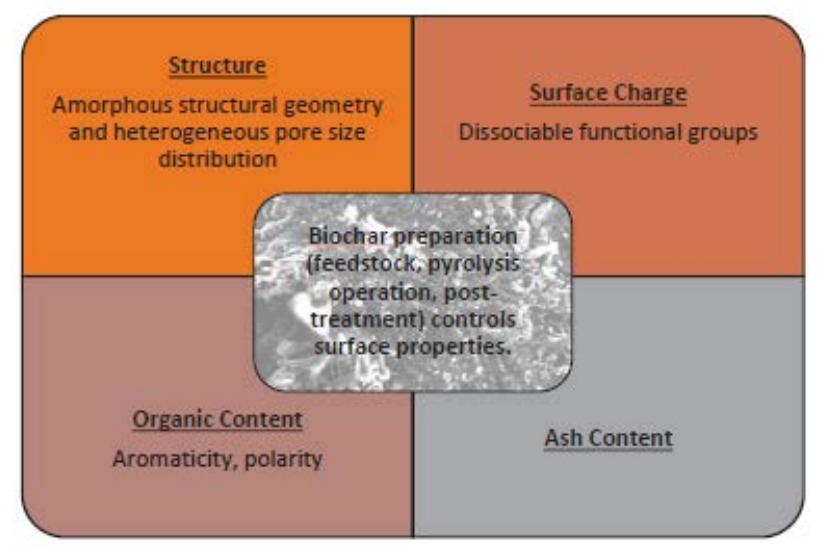

Figure 1. Biochar preparation affects its backbone structure, surface charge, organic content, and ash (mineral) content. These factors subsequently affect kinetics and the equilibrium of adsorption. 


\subsection{Adsorption kinetics of aqueous-phase organic compounds}

Adsorption of dissolved molecules or ions onto porous adsorbents such as biochar is typically described as a mass transfer process (diffusion) followed by adsorbate-adsorbent surface interactions. On this basis, several mathematical kinetic models have been developed. Based on incorporation of consecutive diffusion-adsorption steps (or not), the proposed kinetic models fall into two categories: diffusion-controlled kinetics or reactioncontrolled kinetics.

\subsection{Diffusion-controlled kinetics}

For molecules or ions in water, diffusion into biochar pores includes the following steps $76,77: 1$ ) diffusion in bulk liquid, 2) diffusion in the water film surrounding the porous adsorbent, and 3) diffusion in the liquid contained in the pores, in most cases called intraparticle diffusion.

The first step of mass transfer is diffusion of the adsorbate through the bulk liquid. This occurs nearly instantaneously after adding the adsorbent into the liquid. Its contribution to controlling the diffusion rate is negligible 76,78 . Therefore, diffusion-controlled kinetic models always take the form of film or intraparticle diffusion in adsorption systems 33 .

The second step of mass transfer is film diffusion. Extending from the surface of the adsorbent, liquid forms a relatively stagnant thin film layer that the adsorbate must traverse before reaching the solid surface. In the case of liquid/solid adsorption, this thin film layer is sometimes called the hydraulic boundary layer ${ }^{34}$. If film diffusion is the rate-limiting step, the rate of adsorbate accumulation onto solids over time is driven by the concentration gradient, and can generally be expressed using the simplified linear driving force model (LDF) 77 . In a well-mixed batch reactor, the concentration gradient in the liquid film is negligible; therefore, film diffusion is usually not rate limiting. In column systems, however, the concentration gradient could be significant 76 . Sircar and Hufton compared the simplified LDF model with other more rigorous models such as Fickian Diffusion and Quadratic Driving Force to analyze adsorption column data. They concluded that LDF was suitable for describing the kinetics for column adsorption, in which film diffusion is the rate-limiting process. Furthermore, LDF can be applied to predict breakthrough curves of fixed bed operation.

The third step of diffusion includes pore diffusion, (penetration of the adsorbate to the center of the adsorbent particle) and/or surface diffusion (diffusion of the adsorbate along the interior surface of the pores). These two types of diffusion are difficult to distinguish in practice ${ }^{34}$. If the adsorbate molecules encounter the greatest resistance during the third step, pore/surface diffusion will be rate limiting. Therefore, the mass balance will only characterize the adsorbate in the solid phase since changes of adsorbate concentration in the bulk liquid and film are negligible. In this case, a control volume is modeled as a thin, annular layer of adsorbent bounded by concentric spheres at radii of $r$ and $r+d r$, and the basic mass balance relationship is written as 34 :

Rate of change of mass of adsorbate stored in the annulus between the two concentric spheres=flux of adsorbate diffusing into the annulus at $r+d r$-flux of adsorbate diffusing out of the annulus at $r$. 
By substituting flux $(\mathrm{J})$ in the mass balance equation with its pseudo-Fick's law expression ${ }^{79}$, the homogenous diffusion model can provide insight into changes in $Q$ (amount adsorbate per unit mass of adsorbent) in time and space, as shown in Eq. ${ }^{80}$ :

$\frac{\partial Q}{\partial t}=\frac{D_{s}}{r^{2}} \frac{\partial}{\partial r}\left(r^{2} \frac{\partial Q}{\partial r}\right)$ Eq. 1

where $D_{s}$ refers to the effective surface diffusion coefficient, which is assumed to be constant for the particle, and $r$ is the distance to the center of the adsorbent particle.

Many special-case rate models have been developed, including the homogenous surface diffusion model (HSDM) ${ }^{81}$, which considers only surface diffusion, whereas the pore diffusion model (PDM) only accounts for pore diffusion $42,82,83$. Since it is difficult to distinguish between pore diffusion and surface diffusion, the intraparticle model, a general homogenous diffusion model ${ }^{80}$, is commonly used to group pore and surface diffusion together.

Initial and boundary conditions must be considered to solve the intraparticle diffusion rate equations as $Q$ varies over time 33,34 . For example, the initial condition for the entire adsorbent particle at time 0 is $Q=0$ (zero uptake of adsorbate). The boundary conditions can include 1) no gradient of $Q$ at the center of the particle and 2) equilibrium conditions between solid and solution phases, i.e., equilibrium isotherm $\left(Q_{e}=f\left(C_{e}\right)\right)^{34}$.

In the case of biochar adsorbents, diffusion-controlled kinetics are appropriate when adsorption of organic chemicals is limited by steric hindrance, i.e., the minimum critical diameter is close to the biochar pore aperture $(2 \mathrm{~nm} \text { to } 50 \mathrm{~nm})^{24,49}$, as exemplified in Section 2.1 .

\subsection{Reaction-controlled kinetics}

Another case to consider is the "adsorption reaction", wherein adhesion of the adsorbate onto the solid surface's adsorption sites is rate limiting, thereby controlling the overall adsorption rate. Accordingly, reactioncontrolled kinetic models characterize only the last step of adsorption, treating the rate of diffusion as negligible. The reaction rate-limiting kinetic approach is more appropriate for binding with adsorption sites via ion exchange or sharing electron pairs via covalent or ionic bonds 40 .

The mathematical expressions of pseudo first-order (PFO) ${ }^{84}$ and pseudo second-order (PSO) rates 85,86 are illustrated in Eq. 2 and Eq. 3, respectively:

$\frac{d Q}{d t}=k_{1}\left(Q_{e}-Q\right)$ Eq. 2

$\frac{d Q}{d t}=k_{2}\left(Q_{e}-Q\right)^{2}$ Eq. 3

where $Q$ (mass adsorbate/mass adsorbent) is the mass adsorption capacity at time $t$, $Q$ e is the capacity at equilibrium, and $k 1$ and $k 2$ are the pseudo first-order and second-order rate constants, respectively. 
These two adsorption reaction models are used when adsorption itself is the rate-limiting step during the entire transport-adsorption process. For example, formation of a covalent bond between adsorbate and adsorbent or strong physical adsorption, such as ion exchange processes, are usually considered reaction rate-limited. The adsorption of positively ionized methyl violet on canola straw biochar at $\mathrm{pH} \mathrm{7-8} \mathrm{is} \mathrm{an} \mathrm{example} \mathrm{of} \mathrm{first-order}$ kinetics, as it was reportedly dominated by ion exchange due to the opposite charge of the biochar's oxygencontaining functional groups ${ }^{87}$. Misuse of PFO kinetics can lead to inappropriate interpretation of the relation between kinetics and mechanisms. For example, weak physical adsorption was observed in a study on estrone adsorption to activated carbon ${ }^{88}$. The researchers postulated that hydrophobic interactions were the dominant adsorption mechanism. However, the kinetic rate of adsorption was characterized using the PFO model, which is more suitable for reaction rate-limited processes such as covalent/coulombic binding.

Kinetic models provide direct information on the rate of diffusion or reaction. A higher diffusion or reaction rate constant indicates faster uptake of the adsorbate. Besides providing straightforward information, adsorption kinetics derived from batch tests are important in modeling the fate and transport of adsorbates through porous media such as soil, subsurface aquifers, and other engineering environments because dynamic fate and transport models all include terms for adsorption 33,76 . From the perspective of water treatment engineering, kinetic models are a prerequisite for predicting fixed bed adsorption performance. While fitting experimental data to kinetic models is necessary, it is not sufficient to extrapolate mechanistic information. To achieve deeper comprehension of adsorptive behavior, batch kinetic studies combined with other approaches may be necessary to elucidate the underlying mechanism of adsorption (e.g., covalent binding or physical adsorption) ${ }^{33,89}$. Complimentary studies on adsorption kinetics, isotherms, thermodynamics, and characterization of surface properties, accompanied by adequate numerical analysis are needed to elucidate adsorption mechanisms.

\subsection{Adsorption mechanisms of organic micropollutant binding to biochar}

In this section, the binding mechanisms of organic micropollutant adsorption onto porous biochar are described. In this review, the "mechanism of adsorption" refers to the mechanism of actual attachment, regardless of molecule/ion diffusion. Therefore, "pore filling", which is mentioned in some articles as an adsorption mechanism ${ }^{31}$, is excluded from this discussion because it does not characterize attachment. Likewise, in the context of this review, absorption is not considered as an independent category of interaction. Schwarzenbach

et al. ${ }^{90}$ describes the partitioning of organic compounds as intermolecular interactions that are weakened in one phase and formed within (absorption) or on the surface (adsorption) of a new phase. Therefore, the fundamental difference between absorption and adsorption is the location where the intermolecular interactions between organic molecules and phases occurs.

Attachment via adsorption is a process that takes place spontaneously since the associated free energy is negative. The driving force of attachment is the sum of a number of forces contributing to the total free energy of adsorption ${ }^{91}$. Driving forces include intra- and inter-molecular interactions due to electrostatic attractions such as covalent bonding, coulombic attraction, and dipole interactions. Dipole interactions can include hydrogen bonding ( $\mathrm{H}$-bonding), $\pi$-interaction, dipole-dipole interaction (Keesom interactions), dipole-induced dipole interaction (Debye interactions), charge-dipole interactions, and fluctuating dipoles (dispersive forces/London Forces). 
For adsorption of organic molecules onto carbonaceous materials, van der Waals forces have been included as one type of non-coulombic interaction, in addition to $\mathrm{H}$-bonding and $\mathrm{n} /$ dipole interactions 92,93 . However, this classification is problematic because "van der Waals forces" is used by some to describe the totality of all intermolecular non-covalent forces, while others use it to describe subsets of intermolecular forces ${ }^{94}$. Since this term is lacking in physical meaning and is insufficiently descriptive, the use of "van der Waals forces" to describe adsorption mechanisms should be avoided.

Hydrophobic interactions between non-polar moieties has also been considered a mechanism for adsorption attachment ${ }^{31}$. However, hydrophobic interaction is not an intermolecular force. It is a non-specific interaction that has more to do with decreasing entropy related to chemicals leaving water as opposed to being attracted to adsorbents 94 .

Figure 2 summarizes the potential mechanisms for aqueous-phase organic compound adhesion onto biochar, each of which are described in the following sections.

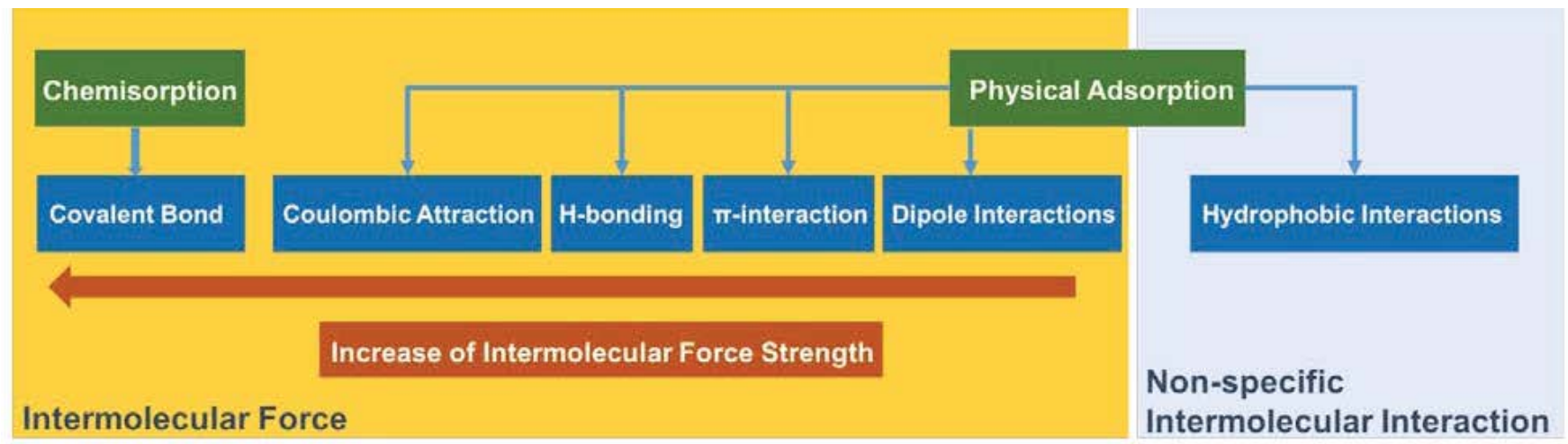

Figure 2. Classification of adsorption mechanisms.

\subsubsection{Covalent bonding}

Covalent bonding is irreversible chemisorption through shared electron pairs and is stronger than any form of non-covalent intermolecular forces. Conversely, adsorption involving non-covalent interactions is usually considered to be physical adsorption (or physisorption). No studies were found showing adsorption of organic compounds to biochar due to covalent bonding (under typical operating temperatures and pressures and in the absence of a catalyst). However, functionalization of carbonaceous biochar with covalent modification is commonly achieved via reactions such as carboxylation, amidation, fluorination, and free radical chemistry 95,96

\subsubsection{Coulombic interaction}

Coulombic interactions occur between two charged moieties, wherein opposite charges on the adsorbate and adsorbent induce coulombic attraction. In the case of adsorption of organic compounds from aqueous solution, coulombic interaction relates to the dissociable functional groups of the organic adsorbate and on biochar's surface. Water quality parameters such as $\mathrm{pH}$ and ionic strength are critical to the dissociation of these functional groups for aqueous adsorption. This is reflected in pKa (acid dissociation constant) values of both adsorbate and biochar functional groups. For example, methyl violet dye $(\mathrm{pKa}=8.64)$ carries a positive charge at $\mathrm{pH}$ values below 9 , while plant-derived biochar carries a negative surface charge (large cation exchange 
capacity) in slightly alkaline water. The dissociation of methyl violet molecules and oxygen-containing functional groups on the surface of canola straw biochar was reported to facilitate coulombic attraction at $\mathrm{pH}$ ranges from 7 to $8{ }^{87}$. In some reports, coulombic interactions are referred to as "electrostatic interactions" 97,98 , which is inaccurate because electrostatic interaction is the fundamental basis for all non-covalent intermolecular forces 99

\subsubsection{Hydrogen bonding}

Hydrogen bonding ( $\mathrm{H}$-bonding) is a special case of strong dipole interaction occurring between a hydrogen donor and acceptor. The hydrogen donor is usually bonded to hydrogen acceptor atoms such as nitrogen $(\mathrm{N})$, oxygen (O), or fluorine (F) 54,96,100 within a functional group, such as $-\mathrm{COOH},-\mathrm{OH},-\mathrm{NH}_{2}$, and electron-rich nsystems. These hydrogen donor/acceptor functional groups on either biochar or organic molecules can form $\mathrm{H}$ bonds. For example, sludge-derived biochar that is rich in hydroxyl groups demonstrated a high affinity for atrazine's amino group ${ }^{101 .}$

Charge-assisted $\mathrm{H}$-bonding (CAHB) is stronger than conventional $\mathrm{H}$-bonding. CAHB includes three categories: double charge-assisted (( \pm CAHB), positive charge-assisted ((+)CAHB), and negative charge-assisted ((-)CAHB) Hbonding ${ }^{102}$. Among these categories, (-)CAHB is often observed for adsorption of dissociable organic compounds onto adsorbent functional groups; therefore, it is highly pH and pKa dependent 62,103 . Gilli et al. ${ }^{102}$ defined (-)CAHB as strong $\mathrm{H}$-bonding between proton donor/acceptor pairs (base as donor and acid as acceptor), e.g., between a carboxyl group and its conjugate acid ([R-COO $\cdots \mathrm{H} \cdots \mathrm{OOC}-\mathrm{R}]^{-}$) or different acid/base pairs. The more similar the pKa values of the groups at either end of the $\mathrm{H}$-bond, the stronger the (-)CAHB 93,104. Therefore, the strongest (-)CAHB occurs between an acid and its conjugated base. Teixido et al. ${ }^{103}$ postulated formation of (-)CAHB between sulfamethoxazole and the carboxylate group on biochar's surface at $\mathrm{pH} 3-7$, where sulfamethoxazole is primarily present as a neutral molecule (Figure 3). The small pKa difference $(\triangle \mathrm{pKa})$ between sulfamethoxazole and COO- allows close sharing of the proton for this type of H-bond 103,105 . For weak organic adsorption on an oxygen rich-biochar surface, CAHB can play a more important role than $\pi$ - or hydrophobic interactions. For adsorption onto a weak acidic maple wood char, Xiao and Pignatello ${ }^{104}$ studied competition of the weak acid 2,4-dichlorophenoxyacetic acid (2-4-D) in comparison to 4-toluic acid or 4-tolyl acetate. They reported that 4-toluic acid had 5 times stronger adsorption than 2,4-D via CAHB, whereas 4-tolyl acetate's affinity was due to hydrophobic interaction. The displacement of 2,4-D on the biochar was $\sim 0.28$ $\mathrm{mol} / \mathrm{mol} 4$-toluic acid ( $0.02 \mathrm{~mol} / \mathrm{mol} 4$-tolyl acetate), which suggested that displacement unlikely occurs for compounds that have different adsorption mechanisms, i.e., CAHB and hydrophobic interaction. Ni et al. ${ }^{93}$ studied the adsorption of allelopathic aromatic acid ions on biochar. They postulated that biochar's carboxyl acid groups can undergo proton exchange with water molecules, and that the allelopathic aromatic acid ions subsequently form hydrogen dicarboxylate conjugate pairs (low $\Delta \mathrm{pKa}$ ). Therefore, CAHB provided covalent-like interaction with an enthalpy value $\sim 100 \mathrm{~kJ} / \mathrm{mol}$. 


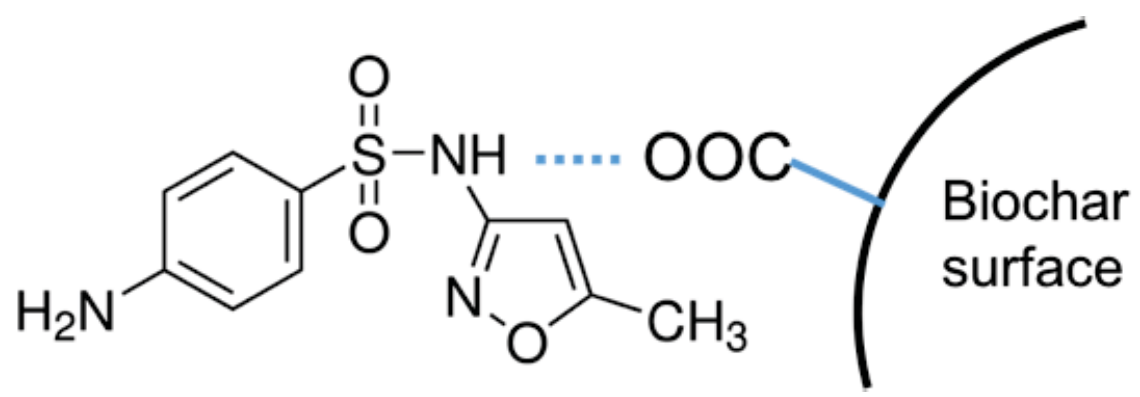

Figure 3. Sulfamethoxazole interaction with a COO- group on biochar's surface via negative charge-assisted hydrogen bonding ((-)CAHB). The dashed line denotes $\mathrm{H}$-bonding.

\subsection{4, $\pi$-interaction}

Another type of dipole interaction is n-interaction, which is weaker than $\mathrm{H}$-bonding. This term is used to interpret attractions between neutral organic molecules and electron rich $\pi$-systems. A $\pi$-system is usually a functional group with n-bonds, which result from the overlap of diffusive electron orbitals. n-systems such as $\mathrm{C}=\mathrm{C}$ double bonds or aromatic rings can be attractive to polar molecules and other $\pi$-systems. The aromaticity of biochar usually increases with pyrolysis temperature, since most of the aliphatic structures are destroyed 106,107 . Polymeric hybrid adsorbents such as ion exchange resins also contain aromatic rings ${ }^{108}$. An aromatic $\pi$-system is electron rich and can either enhance existing $\mathrm{H}$-bonds or behave as proton acceptors. Mahmudov et al. ${ }^{109}$ found that a graphite-like activated carbon with an aromatic sheet structure favored perchlorate adsorption due to $\pi$-system facilitation 107,109 . Due to the highly electronegative nature of $\pi$-systems, cation attraction is also favorable.

Intermolecular attractions between $\pi$-systems, known as $\pi-\pi$ interactions, occur as well. $\pi-\pi$ interactions occur between oppositely polarized quadrapoles of arene systems oriented in a parallel-planar fashion ("stacking") ${ }^{103}$. For instance, when the p-aminosulfonamide rings of sulfamethazine are present as r-electron acceptors, they can attach to the aromatic sheet structures ( $\pi$-electron donor) of hardwood litter biochar ${ }^{103}$. Opposite polarization of aromatic systems induces their opposite preference for electrons. Therefore, the most widely adopted conceptual model to describe $\pi-\pi$ interaction is the $\pi$-electron donor-acceptor model (EDA) 100,110 . The conjugated ring system of the graphene subunit on biochar's surface makes it an electron-rich $\pi$ electron donor, which can pair electron-withdrawing substituents with organics with electron-poor ring systems, such as heteroaromatic rings or benzene rings. Sander and Pignatello ${ }^{111}$ found the adsorption affinities associated with graphene units of wood biochar showed a trend of nitrobenzene>toluene>benzene. This trend attributes to the strongest electron- withdrawing effect of the nitro group, making nitrobenzene the most electron deficient among the three compounds tested. Organic compounds with $\pi$-electron donor properties can also be attracted to electron-depleted regions on biochar, such as the center of the graphene unit 27,112 . Using charge-transfer absorbance in the UV-visible absorption spectrum, $\pi-\pi$ EDA interactions can be characterized 110,113 . Raman, nuclear magnetic resonance (NMR) spectroscopy, and fluorescence techniques are also applied to characterize other $\pi$ interactions 96 .

\subsubsection{Other dipole interactions}

Other dipole interactions include permanent dipole interactions (also known as Keesom interactions), dipoleinduced dipole interaction (Debye interactions), and fluctuating dipoles (dispersive forces or London Forces). 
These intermolecular forces may be applicable for adsorbates containing polar functional groups such as alkyl halide, ether, nitrile, etc. 96,100 . As the temperature of heat treatment increases, dipolar forces should decrease due to the development of aromaticity and non-polarity on biochar caused by ring fusion, which forms clusters with high carbon content. Alternately, $\pi-\pi$ EDA forces vary in the opposite manner. Lattao et al. 75 observed consistency in the free energy contribution of combined $\pi-\pi$ EDA and dipole interaction to 1,4dinitrobenzene adsorption on wood biochar over a range of fused ring sizes.

\subsubsection{Hydrophobic interaction}

Hydrophobic interaction is a type of non-specific interaction that is primarily driven by entropy. While its underlying basis is not fully elucidated, hydrophobic interactions are widely believed to occur due to the tendency of non-polar groups to aggregate in water to minimize their contact with water molecules. Since this non-specific interaction is not driven by intermolecular forces with adsorbents, it is inappropriate to use the term "bond" for hydrophobic interactions $44,94,113$. The octanol-water distribution coefficient (Kow) is an indicator of hydrophobicity of organic chemicals. If hydrophobic interaction is the dominant mechanism, adsorption of non-polar chemicals on porous materials would be proportional to Kow values ${ }^{100}$. In the case of phenanthrene adsorbing on a plant residual-derived biochar, this correlation is generally not observed, implying that hydrophobic interactions are not the dominant mechanism of attraction. ${ }^{114}$

\subsection{Quantitative methods for characterizing adsorption equilibrium of aqueous-phase organic micropollutants}

\subsection{Isotherms}

An adsorption isotherm is a quantitative method to characterize adsorbate equilibrium between aqueous and solid phase at a constant ambient temperature. Typical isotherm models used for organic contaminants include Langmuir, Freundlich, Toth ${ }^{115}$, Tempkin ${ }^{116}$, Dubinin-Radushkevich ${ }^{117}$, and others. The derivations of isotherm models for certain chemicals are based on the binding affinity/strength distribution on the adsorbent

surface ${ }^{34}$. Assuming one adsorbate molecule binds with a single site on the adsorbent, and the total number of adsorption sites on the surface is limited, binding affinity of the chemical to the adsorption site is usually indicated by a partitioning or distribution coefficient, $\mathrm{K}$, expressed as shown in Eqs. 4 and 5:

$\equiv S+A(a q) \leftrightarrow \equiv S A$ Eq. 4

$K=\frac{C_{\equiv S A}}{C_{\equiv S A} C_{A(a q)}}$ Eq. 5

where $\equiv S$ is the adsorption site on the surface, $A(a q)$ is the adsorbate molecule in the aqueous phase, $\equiv S$ is adsorbate-adsorption site complex, $\mathrm{K}$ is the distribution coefficient, and $\mathrm{C}$ represents the concentration of the respective species.

The derivation of the Langmuir isotherm assumes that a surface has a uniform $\mathrm{K}$ value, i.e., all adsorption sites are identical and have the same affinity for a certain adsorbate. Also, the binding of a single adsorbate does not interfere with the binding of other molecules. The sites on the adsorbent can be classified as $Q_{=S A}$, the occupied sites per unit mass of adsorbent (adsorption capacity), or $Q_{=s}$, the unoccupied sites. The total adsorption sites 
per unit mass of adsorbent is Qmax. By substituting these values into the expression for K, the Langmuir isotherm model is generated (Eq. 6):

$Q_{\equiv S A}=\frac{Q_{\max } K C_{A}}{K C_{A}+1}$ Eq. 6

The term $\frac{K C_{A}}{K C_{A}+1}$ is also called the fractional coverage of the sites with a distribution value of $\mathrm{K}^{34}$ because it equals $\frac{Q_{\equiv S A}}{Q_{\max }}$. Artificial polymeric adsorbents, such as ion exchangers are considered to have adsorption sites with a single binding affinity $\mathrm{K}^{118}$, which is usually denoted as $\mathrm{KL}$ in the case of the Langmuir isotherm. Therefore, the Langmuir isotherm is often a good choice for modeling removal of inorganic ions 119,120 . However, equilibrium data for adsorption of organic compounds on biochar and other carbonaceous materials is rarely fit to the conventional Langmuir isotherm.

In the case that multiple types of sites having different $K$ values are present on the adsorbent surface, the Langmuir isotherm model for each type of adsorption site can be summed to obtain the multi-site Langmuir isotherm (Eq. 7):

$Q_{\text {total }}=\sum_{j=1}^{n} \frac{Q_{\max , j} K_{j} C}{1+K_{j} C}$ Eq. 7

where $\mathrm{K}_{\mathrm{j}}$ is the binding affinity of each type of adsorption site (j). The multi-site Langmuir isotherm has been applied, e.g., in the adsorption of phosphate onto soil via ion exchange, where the soil samples may have two to three types of adsorption sites 121,122 .

For many adsorbents, the distribution of site types is variable and sites with single-value or multiple-value Ks are difficult to find. This necessitates use of the Freundlich isotherm, in which site distribution is described as semicontinuous. The adsorbent comprises a small number of sites with high affinities (larger $\mathrm{K}$ values) and an exponentially increasing number of sites with steadily decreasing $K$ values. A small group of sites is considered to have nearly uniform $\mathrm{K}$ values (between $\mathrm{K}$ and $\mathrm{K}+\mathrm{dK}$ ). In this differential area, it is assumed that the concentration of total adsorption sites can be described as a distribution associated with $\mathrm{K}$ (Eq. 8) ${ }^{34,123}$ :

$\Phi_{\text {diff }}=\alpha K^{-n}$ Eq. 8

where $\Phi_{\text {diff }}$ is the distribution function and $\alpha$ and $\mathrm{n}$ are constants $(0 \leq n \leq 1)$. The differential adsorption capacity, $Q_{\text {diff }}$, for this area can be characterized by the Langmuir isotherm, modified as shown in Eq. 9:

$Q_{\text {diff }}=\Phi_{\text {diff }} \frac{K C_{A}}{K C_{A}+1}$ Eq. 9

By substituting Eq. 8 into Eq. 9, and integrating the adsorption capacity over all sites ( $\mathrm{K}$ from 0 to $\infty$ ), Eq. 10 is obtained to describe adsorption capacity:

$Q=\int_{0}^{\infty} \frac{\alpha K^{1-n} C_{A}}{K C_{A}} d K$ Eq. 10 
Halsey and Taylor ${ }^{123}$ developed the solution for Eq. 10, yielding the Freundlich isotherm (Eq. 11):

$\mathrm{Q}=K_{f} C_{A}^{n}$ Eq. 11

Where $\mathrm{K}$ is the Freundlich parameter, which is usually denoted as $\mathrm{Kf}$ in this case, reflecting adsorption capacity. The $\mathrm{n}$ term ranges from 0 to 1 , and is an indicator of distribution of binding affinity or binding energy on the adsorbent surface. The more drastically thebinding affinity changes (indicating the existence of remarkably strong affinity sites) across the adsorbent surface, the smaller the $\mathrm{n}$ value. For carbonaceous materials such as biochar, the adsorption of organic contaminants from dilute solution $(C<500 \mu \mathrm{g} / \mathrm{L}$ ) is often characterized by an $n$ value between 0.2 and $0.7^{34}$. Compared to the Langmuir isotherm, the Freundlich isotherm often fits better in the case of adsorption of organic chemicals onto carbonaceous materials, possibly because of the uneven distribution of adsorption sites. For example, in a study adsorbing the acidic herbicides dicamba and 2,4,5-T on carbon nanotubes, Pyrzynska et al. ${ }^{124}$ found that the Freundlich isotherm provided a better fit than Langmuir for describing adsorption equilibrium.

The Freundlich isotherm was incorrectly described as an empirical model in some literature ${ }^{125,126}$. However, as shown here, the Freundlich isotherm has a theoretical basis and is related to the Langmuir model, i.e., integration of the Langmuir isotherm yields the Freundlich equation ${ }^{118}$. Several studies found that the adsorption/exchange of fluoride and cobalt onto ion exchange resins can fit both Langmuir and Freundlich at certain Caq ranges ${ }^{120,127}$, which supports the inherent relationship between these two isotherm models.

In cases when a single organic compound is present at trace amounts in water, simple isotherms such as the Freundlich model can be used to model adsorption (providing a good linear fit when plotted on log-scale coordinates) ${ }^{111}$. However, in the case of single-solute adsorption, there is a maximum threshold of initial organic concentration, beyond which more complex isotherm models are needed to better predict adsorption behavior ${ }^{128,129}$. Shimubuku et al. ${ }^{129}$ found that the concentration threshold correlated negatively with the compounds' adsorbability, but correlated positively with the competing dissolved organic matter by adopting the Ideal Adsorbed Solution Theory-Equivalent Background Compound model (IAST-EBC), which is based on Freundlich parameters.

An isotherm is a useful tool to aid in numeric characterization of adsorption behavior as isotherm equations can predict adsorption capacities on solid phases at different equilibrium aqueous-phase concentrations. The Langmuir constant $Q_{\max }$ is the measure of a monolayer's maximum adsorption capacity, and the Freundlich parameter $\mathrm{Kf}$ can also roughly reflect adsorption capacity when comparing multiple adsorbent-adsorbate systems. Besides providing straightforward information, such as illustrating the equilibrium status of adsorbate molecules between aqueous and solid phases, isotherm equations are also an important boundary condition to solve transport equations for an adsorbate in fixed bed reactors 34,130 .

The distribution coefficient $\mathrm{K}$ used in derivation of isotherms is related to the thermodynamic equilibrium constant $\left(K_{C}=\exp \left(-\Delta G^{0} / R T\right)\right.$ ), and the surface site distribution function $\Phi_{\text {diff }}$ is also related to $K$. These underlying thermodynamic bases of isotherms can provide insight into adsorption mechanisms, adsorbent surface properties, and the degree of adsorbent affinity ${ }^{131}$. 


\subsection{Thermodynamics of adsorption}

Thermodynamics, like isotherms, play an essential role in characterizing adsorption equilibrium and mechanisms. Important thermodynamic parameters for adsorption include the 601 change of enthalpy/heat $\left(\Delta \mathrm{H}^{0}\right)$, change of entropy $\left(\Delta \mathrm{S}^{0}\right)$, and the standard change in Gibb's free 602 energy $\left(\Delta \mathrm{G}^{0}\right)$, which are related as shown in Eq. 12:

$\Delta G^{0}=\Delta H^{0}-T \Delta S^{0}$ Eq. 12

where $\mathrm{T}$ is the ambient temperature $(\mathrm{K})$.

The dimensionless equilibrium constant of adsorption, $\mathrm{K}_{\mathrm{C}}$, is related to $\Delta \mathrm{G}^{0}$ (Eq. 13):

$\Delta G^{0}=-R T \ln K_{c}$ Eq. 13

where $R$ is the ideal gas constant.

The equilibrium constant can be derived from the constants in the Langmuir, Freundlich, and other isotherm models ${ }^{78}$. Therefore, the two-phase equilibrium model of adsorption, i.e., an isotherm, is related to the thermodynamic properties of the adsorption system (both adsorbate and adsorbent). In this section, an overview of the thermodynamics of adsorption is provided, yielding additional quantitative insights into the equilibrium of organic micropollutant adsorption and the related binding mechanisms.

\subsubsection{Isosteric heat of adsorption}

Isosteric heat of adsorption is the differential heat of adsorption at a fixed surface (or adsorption capacity, Qe) at equilibrium. This term was originally introduced for quantifying gaseous-phase adsorption ${ }^{132-134}$, and was adapted for adsorption from aqueous solution 36,135 . It is defined according to the Clausius-Clapeyron equation (Eq. 14):

$\Delta H_{s t}=R \frac{d \ln C_{e}}{d 1 / t} \mid Q_{e}$ Eq. 14

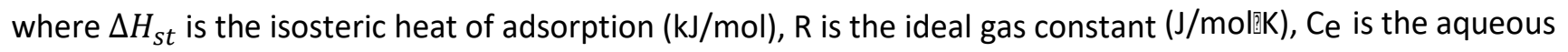
phase concentration at equilibrium ( $\mathrm{mol} / \mathrm{L})$, and $\mathrm{T}$ is temperature $(\mathrm{K})$.

Accordingly, isosteric heat of adsorption at certain adsorbent coverages can be experimentally determined by obtaining $\mathrm{C} e$ values using isotherm curves at multiple ambient temperatures, and calculating the slope of the InCe versus $1 / T$ curve. Figures $4 \mathrm{~A}$ and $4 \mathrm{~B}$ are typical profiles of isosteric heat as a function of adsorbent surface coverage. 

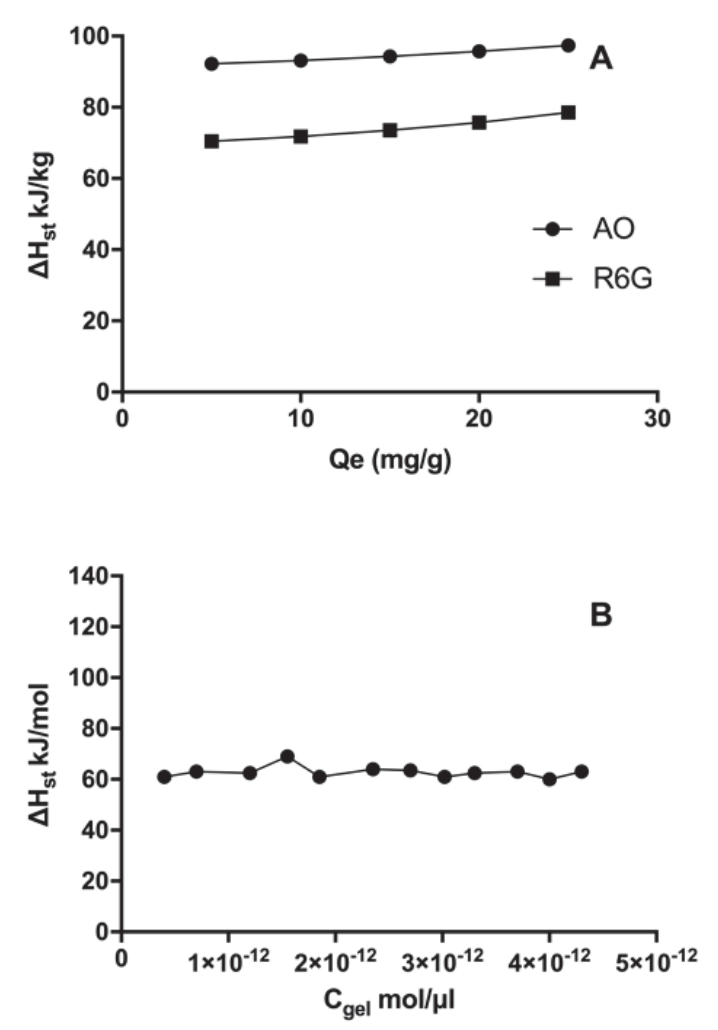

Figure 4. A) Isosteric heat of adsorption of the organic dyes acridine orange (AO) and rhodamine 6G (R6G) using foodwaste-derived biochar with varying surface loading, adapted from Parshetti et al. ${ }^{136}$, and B) Isosteric heat change of lysozyme adsorption using a sepharose 631 ion exchange resin, adapted from Chen et al. ${ }^{137}$.

Differences in the trends of isosteric heat change as a function of surface loading stem from different adsorption site properties. Since isosteric heat is a widely used term that is indicative of energy and strength of binding interactions 138,139 , the adsorption site distribution of an adsorbent can be postulated from the $\Delta H_{s t}$ versus Qe profile. For adsorption of organic dyes on biochar, Figure 4A shows isosteric heat changing with surface coverage. Since foodwaste-derived biochar has highly heterogeneous adsorption sites due to the intrinsic variability in the feedstock, the organic dye binding energy is highest for the left-hand part of the curve, because low-energy binding sites are more favorable. As low-energy sites are gradually occupied, high- energy sites bind with dye molecules, absorbing more heat at high surface coverage ${ }^{136}$. This type of isosteric heat distribution aligns with equilibrium isotherm models describing multi-type site distribution, such as the Freundlich isotherm 34 . Figure 4B shows the isosteric heat of lysozyme binding with SP-Sepharose ion exchange resin. Lysozyme binding using the ion exchange resin is well characterized using the Langmuir model, which assumes adsorption sites have a fixed binding affinity and no interaction among adsorbed molecules. The isosteric heat of adsorption should therefore not change with surface adsorbate loading 34,140 .

Weber and Talapatra ${ }^{139}$ proposed a relationship between isosteric heat $\left(\mathrm{q}_{s t}=\Delta H_{s t}\right)$ and binding energy (Eb), as shown in Eq. 15:

$q_{s t}=E_{b}+2 k T$ Eq. 15 
where $\mathrm{Eb}$ is the binding energy of the adsorbate molecule adsorbing to a certain type of adsorption site $(\mathrm{J}), \mathrm{k}$ is the Boltzmann constant $(\mathrm{J} / \mathrm{K})$, and $\mathrm{T}$ is the temperature $(\mathrm{K})$.

This equation shows that the binding energy can be extracted from isosteric heat, which is derived from adsorption isotherm measurements 139,140 .

\subsubsection{Enthalpy change of adsorption}

Use of the term "enthalpy change of adsorption" and the related, but different, "isosteric heat of adsorption", is often confusing, and in many cases the isosteric heat of adsorption is incorrectly described as heat/enthalpy of adsorption 135,141 . Ideally, the enthalpy change of adsorption can be obtained by integrating the isosteric heat from zero to the maximum surface coverage, and the integral of enthalpy should be used to estimate free energy change of adsorption 142,143 . However, this approach can be difficult as isosteric heat values can be unpredictable and it is difficult to determine the maximum coverage (Qe).

Another approach to estimating the enthalpy change of adsorption is based on the van't Hoff equation at a constant pressure (Eq. 16):

$\Delta H^{0}=-R \frac{d \ln K_{C}}{d(1 / T)}$ Eq. 16

which can also be written in the form of Eq. 17:

$\ln K_{C}=\frac{\Delta H^{0}}{R T}+\frac{\Delta S^{0}}{R}$ Eq. 17

This equation is derived from Eqs. 12 and 13. By plotting InKc versus $1 / T, \Delta H^{O}$ is obtained from the slope (noting that enthalpy change of a given system is not impacted by ambient temperature), and $\Delta S$ can be derived from the intercept. Therefore, knowing $\mathrm{Kc}_{c}$, the thermodynamic equilibrium constant, is critical for the estimation of enthalpy and free energy change of adsorption. According to the expression, $\mathrm{K}_{\mathrm{c}}$ is a dimensionless constant. here are a number of studies simply using the partitioning coefficient $K_{p}=C_{s} / C_{e}$, as the thermodynamic equilibrium constant, where $C_{s}$ is the adsorbate concentration on the solid $\left(\mathrm{mg} / \mathrm{g}\right.$ ) and $\mathrm{Ce}_{\mathrm{e}}$ is that in liquid $(\mathrm{mg} / \mathrm{L})$ $135,144,145$. However, in this relationship, $\mathrm{Kp}$ is apparently not dimensionless based on the units of $\mathrm{Cs}_{\mathrm{s}}$ and $\mathrm{Ce}$. Additionally, at a fixed temperature, the partitioning coefficient is not constant for an adsorption system that behaves as a non-linear isotherm. Therefore, Kp cannot be directly used for estimating the enthalpy of adsorption. Kumar et al. ${ }^{146}$ incorrectly applied partitioning coefficients, which varied with equilibrium aqueous-

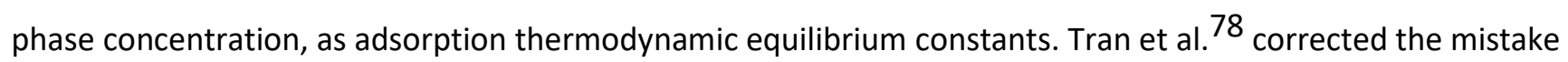
and generated a single $K_{C}$ value at a fixed temperature. Adsorption equilibrium constants can be derived from isotherm parameters, such as the Langmuir constant $(\mathrm{KL}){ }^{147,148}$ and the Freundlich constant $(\mathrm{Kf})^{78,149}$.

The sign of the enthalpy change indicates whether the reaction is endothermic (positive) or exothermic (negative). Vithanage et al. ${ }^{35}$ used van't Hoff's equation for estimating enthalpy of tea waste-derived biochar adsorbing carbofuran from the aqueous phase. They found $\Delta H^{\circ}$ to be approximately $-46 \mathrm{~kJ} / \mathrm{mol}$. The negative value indicates that adsorption was an exothermic process. Endothermic adsorption of organic pollutants from the aqueous phase onto carbonaceous materials has also been observed ${ }^{135,150,151}$. For example, Chen et 
al. 150 estimated the change of enthalpy for 1,3-dinitrobenzene adsorption on pine needle-derived biochar as 14 $\mathrm{kJ} / \mathrm{mol}$, and the value for naphthalene adsorption as $16 \mathrm{~kJ} / \mathrm{mol}$.

Endothermic adsorption can be attributed to the roles of adsorbate-solution or adsorbent-solution interactions or the formation of covalent bonds during adsorption. A large absolute value for change of enthalpy, i.e., greater than $100 \mathrm{~kJ} / \mathrm{mol}$, is indicative of chemisorption via formation of covalent bonds ${ }^{39,152}$. The enthalpy of $\mathrm{H}$-bonds is $\Delta \mathrm{pKa}$-driven; the strongest $\mathrm{H}$-bonds are those in which the difference between the $\mathrm{pKa}$ of the $\mathrm{H}$-donor and the pKa of the $\mathrm{H}$ - acceptor is minimum ${ }^{102}$. Intermolecular forces such as $\mathrm{CAHB}$, which equally or nearly equally share the proton, have "considerable covalent character", with enthalpy changes at values upward of $37 \mathrm{~kJ} / \mathrm{mol}$ 43 (the reported largest among $\mathrm{H}$-bonds). In the case of aqueous-phase adsorption, endothermic adsorption occurs when adsorbate-water or adsorbent-water interactions are overcome before the adsorbate adheres onto the adsorbent. The heat-consuming steps include:

1) adsorbate diffusion in the water matrix, which requires breaking hydrogen bonds formed among water molecules 151

2) adsorbate diffusion in adsorbent pores 153,154 ,

3) adsorbate replacing pre-adsorbed water molecules, which also requires breaking hydrogen bonds between water molecules and adsorbent.

Increasing adsorption temperature promotes external heat input and therefore has a positive impact on endothermic adsorption capacity.

\subsubsection{Free energy change of adsorption}

The ability of an adsorption interaction to proceed spontaneously is energetically described by the change in Gibbs free energy of the process, $\Delta G^{O}$. When diffusion-adsorption can be driven or hindered by a collection of factors such as concentration gradient, coulombic forces, or other non-coulombic interactions, $\Delta G^{\circ}$ reflects the balance between these driving/hindrance forces. The absolute value of $\Delta G^{O}$ reflects the degree of spontaneity, where more energetically favorable adsorption usually has a higher absolute value ${ }^{148}$. A negative $\Delta G^{\circ}$ value indicates that the driving forces promote adsorption rather than hinder adsorption. Physical adsorption is usually spontaneous, with an overall negative $\Delta G^{\circ}$ value ${ }^{78}$. Experimentally determined $\left|\Delta G^{\circ}\right|$ of spontaneous organic micropollutant adsorption on biochar can be on the order of $10 \mathrm{~kJ} / \mathrm{mol}$ or less, and rarely exceeds 50 $\mathrm{kJ} / \mathrm{mol} 150,155,156$.

Similar to the standard enthalpy change, $\Delta G^{O}$ is also related to $\mathrm{K}_{\mathrm{C}}$ (Eq. 16). Therefore, the estimation of $\Delta G^{O}$ depends heavily on an accurate understanding of $\mathrm{K}_{\mathrm{c}}$, which is a strictly dimensionless value, as mentioned earlier. It is relatively straightforward to experimentally derive the overall free energy change of adsorption from adsorption isotherms. However, partitioning overall free energy change into multiple contributions stemming from different mechanisms (coulombic and non-coulombic driving forces) requires molecular dynamic simulation 157 or thermodynamic models derived from experimental approaches 27,75 . 


\subsection{Conclusions and Future Directions}

The fate of organic micropollutants in natural and engineered environments is strongly impacted by their adsorptive behavior. Accordingly, for design of effective biochar-based WRRF treatment processes, insight into the adsorptive driving forces, molecular-scale interactions, and equilibrium is helpful for achieving engineering aims including improved prediction, validation, and removal performance using this emerging adsorbent material.

Specific findings from each of the review's four objectives are summarized together with research needs to address current knowledge gaps using biochar as a micropollutant adsorbent.

\section{1) Link biochar surface properties with its adsorption abilities.}

Biochar's morphological and pore structure, surface charge, organic content, and the presence of dissociable functional groups on both biochar and adsorbates are key factors affecting kinetics and binding mechanisms of adsorption. The wider range of biochar feedstocks in comparison to activated carbon feedstock leads to greater heterogeneity in biochar surface properties, which can lead to a range of disparate interactions with organics. For instance, biochar's graphene-like unit can increase adsorption efficiency with either $\pi$-electron donor or acceptor properties via $\pi$-EDA interactions. Additionally, high ash content in biochar is more favorable for adsorption of polar organic compounds. Enhanced adsorption of dissociable organic compounds can result from the presence of dissociable biochar functional groups, which either occur naturally or are supplied by post-pyrolysis treatment. It is therefore difficult to claim that biochar can specifically adsorb any given group of compounds, nor is it feasible to ascertain adsorption capacity of a certain compound as a function of surface properties without a full spectrum of biochar characterization. Thus, future biochar research focused on linking surface properties with adsorption capacities should incorporate a full spectrum of surface property characterization with the use of homogeneous model adsorbents, such as graphite, to model non- polar moieties in biochar ${ }^{27}$. Establishing these correlations will enable better extrapolation of adsorption kinetics and mechanisms for a range of biochar/micropollutant combinations.

2) Categorize the kinetics of adsorption of aqueous-phase organic compounds onto biochar.

The kinetics of aqueous-phase adsorption can be categorized in terms of the rate-limiting step. Diffusion-controlled kinetics are usually observed for weak physical adsorption, whereas reactioncontrolled kinetics most often characterize chemical adsorption or strong physical adsorption such as coulombic attraction, which stems from charged functional groups on both the biochar's surface and on micropollutant molecules. Future biochar adsorption research should always incorporate mechanistic analysis in order to select proper kinetic models.

\section{3) Categorize the molecular-scale interactions between organic micropollutants and biochar.}

The intermolecular forces discussed in this review include those associated with organics and biochar, including hydrophobic interaction, dipole interaction, $\pi$-interaction, $\mathrm{H}$-bonding, coulombic attraction, and covalent bonding. Binding mechanisms are closely related to the molecular structures of the organic micropollutants and surface properties of biochar. Qualitative categorization of mechanisms is essential for calculating the contribution of each mechanism to total free energy change of adsorption in thermodynamic models 27 . The engineered solid surface properties can be improved to facilitate dominant binding accordingly. 
4) Review existing quantitative methods for characterizing adsorption equilibrium of organic micropollutants from water.

Adsorption equilibrium can be characterized using isotherm models. Experimental isotherm data can be used to derive fundamental thermodynamic properties characterizing adsorption, including the isosteric heat, enthalpy change, entropy change, and free energy change of adsorption. With this quantitative information, kinetics and mechanisms of adsorption can be further elucidated. For example, diffusioncontrolled adsorption has a high chance of being endothermic, and the extent of total free energy change can indicate whether a reaction is chemisorption or physical adsorption. Therefore, continued work establishing adsorption isotherms is essential for researching adsorptive behavior, as it builds bridges between qualitative and quantitative interpretation of adsorption equilibrium, between molecular interaction and pilot-scale operation, and between batch and continuous-flow reactor performance.

The thermodynamics and mechanisms of adsorption are closely related concepts describing adsorption equilibrium. Elucidation of adsorption mechanisms is not possible without accurately characterizing the thermodynamic profile, and vice-versa. Biochar research to-date is ambiguous with respect to which interactions are involved in binding, resulting in contradictory characterization of adsorption mechanisms and their relation to kinetics or thermodynamics. Future studies would benefit from consistent usage of appropriate terminology for describing adsorption mechanisms. Furthermore, additional biochar-specific thermodynamic modeling is expected to better categorize contributions to energy changes during the adsorption process stemming from different mechanisms.

\section{Conflicts of Interest}

There are no conflicts of interest to declare.

\section{References}

1 R. P. Schwarzenbach, B. I. Escher, K. Fenner, T. B. Hofstetter, C. A. Johnson, U. von Gunten and B. Wehrli, The challenge of micropollutants in aquatic systems, Science, 2006, 313, 1072-1077.

2 B. D. Blair, J. P. Crago, C. J. Hedman and R. D. Klaper, Pharmaceuticals and personal 799 care products found in the Great Lakes above concentrations of environmental concern, Chemosphere, 2013, 93, 2116-2123.

3 M. R. Servos, D. T. Bennie, B. K. Burnison, A. Jurkovic, R. Mclnnis, T. Neheli, A. Schnell, P. Seto, S. A. Smyth and T. A. Ternes, Distribution of estrogens, 17 beta-estradiol and estrone, in Canadian municipal wastewater treatment plants, Sci. Total Environ., 2005, 336, 155-170.

4 R. Hirsch, T. Ternes, K. Haberer and K.-L. Kratz, Occurrence of antibiotics in the aquatic environment, Sci. Total Environ., 1999, 225, 109-118.

5 B. Morasch, F. Bonvin, H. Reiser, D. Grandjean, L. F. de Alencastro, C. Perazzolo, N. Chèvre and T. Kohn, Occurrence and fate of micropollutants in the Vidy Bay of Lake Geneva, Switzerland. Part II: micropollutant removal between wastewater and raw drinking water, Environ. Toxicol. Chem., 2010, 29, 1658-68.

6 P. Verlicchi, M. Al Aukidy and E. Zambello, Occurrence of pharmaceutical compounds in urban wastewater: removal, mass load and environmental risk after a secondary treatment- -a review, Sci. Total Environ., 2012, 429, 123-55.

7 A. M. Vajda, L. B. Barber, J. L. Gray, E. M. Lopez, J. D. Woodling and D. O. Norris, Reproductive disruption in fish downstream from an estrogenic wastewater effluent, Environ. Sci. Technol., 2008, 42, 3407-3414. 
8 D. E. Carey, D. H. Zitomer, K. R. Hristova, A. D. Kappell and P. J. McNamara, Triclocarban Influences Antibiotic Resistance and Alters Anaerobic Digester Microbial Community Structure, Environ. Sci. Technol., 2016, 50, 126-134.

9 P. A. Neale, M. Mastrup, T. Borgmann and A. I. Schäfer, Sorption of micropollutant estrone to a water treatment ion exchange resin, J. Environ. Monit., 2010, 12, 311-317.

10 C. Jung, J. Park, K. H. Lim, S. Park, J. Heo, N. Her, J. Oh, S. Yun and Y. Yoon, Adsorption of selected endocrine disrupting compounds and pharmaceuticals on activated biochars, J. Hazard. Mater., 2013, 263 Pt 2, 702-10.

11 B. D. Blair, J. P. Crago, C. J. Hedman, R. J. F. Treguer, C. Magruder, L. S. Royer and R. D. Klaper, Evaluation of a model for the removal of pharmaceuticals, personal care products, and hormones from wastewater, Sci. Total Environ., 2013, 444, 515-21.

12 S. A. Snyder, S. Adham, A. M. Redding, F. S. Cannon, J. DeCarolis, J. Oppenheimer, E. C. Wert and Y. Yoon, Role of membranes and activated carbon in the removal of endocrine disruptors and pharmaceuticals, Desalination, 2007, 202, 156-181.

13 Y. Yoon, P. Westerhoff, S. A. Snyder and E. C. Wert, Nanofiltration and ultrafiltration of endocrine disrupting compounds, pharmaceuticals and personal care products, J. Memb. Sci., 2006, 270, 88-100.

$14 \mathrm{~S}$. Werle and R. K. Wilk, A review of methods for the thermal utilization of sewage sludge: The Polish perspective, Renew. Energy, 2010, 35, 1914-1919.

15 P. Hadi, M. Xu, C. Ning, C. Sze Ki Lin and G. McKay, A critical review on preparation, characterization and utilization of sludge-derived activated carbons for wastewater treatment, Chem. Eng. J., 2015, 260, 895906.

16 Z. Liu, S. Singer, Y. Tong, L. Kimbell, E. Anderson, M. Hughes, D. Zitomer and P. McNamara, Characteristics and applications of biochars derived from wastewater solids, Renew. Sustain. Energy Rev., 2018, 90, 650-664.

17 Z. Liu, P. McNamara and D. Zitomer, Autocatalytic Pyrolysis of Wastewater Biosolids for Product Upgrading, Environ. Sci. Technol., 2017, 51, 9808-9816.

18 P. J. McNamara, J. D. Koch, Z. Liu and D. H. Zitomer, Pyrolysis of Dried Wastewater Biosolids Can Be Energy Positive, Water Environ. Res., 2016, 88, 804-810.

19 B. Singh, B. P. Singh and A. L. Cowie, Characterisation and evaluation of biochars for their application as soil amendment, Aus. J. Soil Res., 2010, 48, 516-525.

20 Y. Tong, B. K. Mayer and P. J. McNamara, Triclosan adsorption using wastewater biosolids-derived biochar, Environ. Sci. Water Res. Technol., 2016, 2, 761-768.

21 H. McLaughlin, Biofuels Dig., 2016.

22 M. Ahmad, S. S. Lee, S. E. Oh, D. Mohan, D. H. Moon, Y. H. Lee and Y. S. Ok, Modeling adsorption kinetics of trichloroethylene onto biochars derived from soybean stover and peanut shell wastes, Environ. Sci. Pollut. Res., 2013, 20, 8364-8373.

23 L. K. Kimbell, Y. Tong, B. K. Mayer and P. J. McNamara, Biosolids-Derived Biochar for Triclosan Removal from Wastewater, Environ. Eng. Sci., 2017, ees.2017.0291.

24 F. Xiao and J. J. Pignatello, Interactions of triazine herbicides with biochar: Steric and electronic effects, Water Res., 2015, 80, 179-188.

25 N. Hagemann, K. Spokas, H. P. Schmidt, R. Kägi, M. A. Böhler and T. D. Bucheli, Water (Switzerland), $2018,10$.

26 K. A. Thompson, K. K. Shimabuku, J. P. Kearns, D. R. U. Knappe, R. S. Summers and S. M. Cook, Environmental Comparison of Biochar and Activated Carbon for Tertiary Wastewater Treatment, Environ. Sci. Technol., 2016, 50, 11253-11262.

27 D. Zhu and J. J. Pignatello, Characterization of Aromatic Compound Sorptive Interactions with Black Carbon (Charcoal) Assisted by Graphite as a Model, Env. Sci. Technol. 2005, 2033-2041. 
28 M. Ahmad, A. U. Rajapaksha, J. E. Lim, M. Zhang, N. Bolan, D. Mohan, M. Vithanage, S. S. Lee and Y. S. Ok, Biochar as a sorbent for contaminant management in soil and water: A review, Chemosphere, 2014, 99, 19-23.

29 X. Tan, Y. Liu, G. Zeng, X. Wang, X. Hu, Y. Gu and Z. Yang, Application of biochar for the removal of pollutants from aqueous solutions, Chemosphere, 2015, 125, 70-85.

30 D. Mohan, A. Sarswat, Y. S. Ok and C. U. Pittman, Organic and inorganic contaminants removal from water with biochar, a renewable, low cost and sustainable adsorbent - A critical review, Bioresour. Technol., 2014, 160, 191-202.

$31 \mathrm{M}$. Inyang and E. Dickenson, The potential role of biochar in the removal of organic and microbial contaminants from potable and reuse water: A review, Chemosphere, 2015, 134, 232-240.

32 M. B. Ahmed, J. L. Zhou, H. H. Ngo and W. Guo, Adsorptive removal of antibiotics from water and wastewater: Progress and challenges, Sci. Total Environ., 2015, 532, 112-126.

33 Z. Xu, J. Cai and B. Pan, Mathematically modeling fixed-bed adsorption in aqueous systems, J. Zhejiang Univ. Sci. A, 2013, 14, 155-176.

34 M. M. Benjamin and D. F. Lawler, Water Quality Engineering: Physical / Chemical Treatment Processes, Wiley, 2013.

35 M. Vithanage, S. S. Mayakaduwa, I. Herath, Y. S. Ok and D. Mohan, Kinetics, thermodynamics and mechanistic studies of carbofuran removal using biochars from tea waste and rice husks, Chemosphere, 2016, 150, 781-789.

36 S. Builes, S. I. Sandler and R. Xiong, Isosteric Heats of Gas and Liquid Adsorption, Langmuir, 2013, 29, 1041610422.

37 M. C. Crowe and C. T. Campbell, Annu. Rev. Anal. Chem. (Palo Alto. Calif)., 2011, 4, 41-58.

38 S. Chowdhury, R. Mishra, P. Saha and P. Kushwaha, Adsorption thermodynamics, kinetics and isosteric heat of adsorption of malachite green onto chemically modified rice husk, Desalination, 2011, 265, 159-168.

39 J. M. Thomas, The existence of endothermic adsorption, J. Chem. Educ., 1961, 38, 138. 40 Y. S. Ho and G. McKay, A Comparison of Chemisorption Kinetic Models Applied to Pollutant Removal on Various Sorbents, Process Saf. Environ. Prot., 1998, 76, 332-340. 41 T. M. Salem Attia, X. L. Hu and D. Q. Yin, Synthesized magnetic nanoparticles coated zeolite for the adsorption of pharmaceutical compounds from aqueous solution using batch and column studies, Chemosphere, 2013, 93, 2076-85.

42 V. Brauch and E. U. Schlünder, The scale-up of activated carbon columns for water purification, based on results from batch tests-II: Theoretical and experimental determination of breakthrough curves in activated carbon columns, Chem. Eng. Sci., 1975, 30, 539-548.

43 J. J. Pignatello, W. A. Mitch and W. Xu, Activity and Reactivity of Pyrogenic Carbonaceous Matter toward Organic Compounds, Environ. Sci. Technol., 2017, 51, 8893-8908.

44 E. E. Meyer, K. J. Rosenberg and J. Israelachvili, Recent progress in understanding hydrophobic interactions, Proc. Natl. Acad. Sci. U. S. A., 2006, 103, 15739-46.

45 A. Downie, A. Crosky and P. Munroe, in Biochar for Environmental Management: Science and Technology, 2012, pp. 13-32.

46 M. Keiluweit, P. S. Nico, M. G. Johnson and M. Kleber, Dynamic Molecular Structure of Plant Biomass-Derived Black Carbon (Biochar), Environ. Sci. Technol., 2010, 44, 1247-1253.

47 H. Sun, W. C. Hockaday, C. A. Masiello and K. Zygourakis, Multiple Controls on the Chemical and Physical Structure of Biochars, Ind. Eng. Chem. Res., 2012, 51, 3587-3597.

48 C. E. Brewer, V. J. Chuang, C. A. Masiello, H. Gonnermann, X. Gao, B. Dugan, L. E. Driver, P. Panzacchi, K. Zygourakis and C. A. Davies, New approaches to measuring biochar density and porosity, Biomass and Bioenergy, 2014, 66, 176-185.

49 R.-L. Tseng and S.-K. Tseng, Characterization and use of high surface area activated carbons prepared from cane pith for liquid-phase adsorption, J. Hazard. Mater., 2006, 136, 671-680. 
50 J. K. D. M. Ruthven, John Wiley, 1992, 1.

51 A. Mukherjee, A. R. Zimmerman and W. Harris, Surface chemistry variations among a series of laboratoryproduced biochars, Geoderma, 2011, 163, 247-255.

52 A. Mehlich and J. F. Reed, Effect of cation-exchange properties of soil on the cation content of plants, Soil Sci., 1948, 66.

53 J. A. Menéndez, M. J. Illán-Gómez, C. A. L. y León and L. R. Radovic, On the difference between isoelectric point and the point of zero charge of carbons, Carbon, 1995, 33, 1655-1657.

54 IUPAC, IUPAC Compend. Chem. Terminol., 2014, 1670.

55 M. J. Antal and M. Grønli, The Art, Science, and Technology of Charcoal Production, Ind. Eng. Chem. Res., 2003, 42, 1619-1640.

56 T. Wang, M. Camps Arbestain, M. Hedley and P. Bishop, Chemical and bioassay characterisation of nitrogen availability in biochar produced from dairy manure and biosolids, Org. Geochem., 2012, 51, 45-54.

57 B. Chen, D. Zhou and L. Zhu, Transitional Adsorption and Partition of Nonpolar and Polar Aromatic Contaminants by Biochars of Pine Needles with Different Pyrolytic Temperatures, Environ. Sci. Technol., 2008, 42, 5137-5143.

58 A. V. McBeath, R. J. Smernik, M. P. W. Schneider, M. W. I. Schmidt and E. L. Plant, Determination of the aromaticity and the degree of aromatic condensation of a thermosequence of wood charcoal using NMR, Org. Geochem., 2011, 42, 1194-1202.

59 K. Sun, M. Keiluweit, M. Kleber, Z. Pan and B. Xing, Sorption of fluorinated herbicides to plant biomassderived biochars as a function of molecular structure, Bioresour. Technol., 2011, 102, 9897-9903.

60 S. Kang and B. Xing, Phenanthrene Sorption to Sequentially Extracted Soil Humic Acids and Humins, Environ. Sci. Technol., 2005, 39, 134-140.

$61 \mathrm{P}$. Grathwohl, Influence of organic matter from soils and sediments from various origins on the sorption of some chlorinated aliphatic hydrocarbons: implications on Koc correlations, Environ. Sci. Technol., 1990, 24, 1687-1693.

62 F. Lian, B. Sun, Z. Song, L. Zhu, X. Qi and B. Xing, Physicochemical properties of herb- residue biochar and its sorption to ionizable antibiotic sulfamethoxazole, Chem. Eng. J., 2014, 248, 128-134.

63 D. Zhu, S. Kwon and J. J. Pignatello, Adsorption of Single-Ring Organic Compounds to Wood Charcoals Prepared under Different Thermochemical Conditions, Environ. Sci. Technol., 2005, 39, 3990-3998.

64 S. Kwon and J. J. Pignatello, Effect of Natural Organic Substances on the Surface and Adsorptive Properties of Environmental Black Carbon (Char): Pseudo Pore Blockage by Model Lipid Components and Its Implications for N2-Probed Surface Properties of Natural Sorbents, Environ. Sci. Technol., 2005, 39, 7932-7939.

65 J. J. Pignatello, S. Kwon and Y. Lu, Effect of Natural Organic Substances on the Surface and Adsorptive Properties of Environmental Black Carbon (Char): Attenuation of Surface Activity by Humic and Fulvic Acids, Environ. Sci. Technol., 2006, 40, 7757-7763.

66 A. Enders, K. Hanley, T. Whitman, S. Joseph and J. Lehmann, Characterization of biochars to evaluate recalcitrance and agronomic performance, Bioresour. Technol., 2012, 114, 644-653.

67 K. K. Shimabuku, J. P. Kearns, J. E. Martinez, R. B. Mahoney, L. Moreno-Vasquez and R. S. Summers, Biochar sorbents for sulfamethoxazole removal from surface water, stormwater, and wastewater effluent, Water Res., 2016, 96, 236-245.

68 X. Gai, H. Wang, J. Liu, L. Zhai, S. Liu, T. Ren and H. Liu, Effects of Feedstock and Pyrolysis Temperature on Biochar Adsorption of Ammonium and Nitrate, PLoS One, 2014, 9.

69 K. Sun, M. Kang, Z. Zhang, J. Jin, Z. Wang, Z. Pan, D. Xu, F. Wu and B. Xing, Impact of Deashing Treatment on Biochar Structural Properties and Potential Sorption Mechanisms of Phenanthrene, Environ. Sci. Technol., 2013, 47, 11473-11481. 
70 P. Zhang, H. Sun, L. Yu and T. Sun, Adsorption and catalytic hydrolysis of carbaryl and atrazine on pig manurederived biochars: Impact of structural properties of biochars, J. Hazard. Mater., 2013, 244-245, 217224.

$71 \mathrm{H}$. Jin, X. Wang, Z. Gu and J. Polin, Carbon materials from high ash biochar for supercapacitor and improvement of capacitance with HNO3 surface oxidation, J. Power Sources, 2013, 236, 285-292.

72 A. Ahmadpour and D. D. Do, The preparation of active carbons from coal by chemical and physical activation, Carbon, 1996, 34, 471-479.

$73 \mathrm{X}$. Jing, Y. Wang, W. Liu, Y. Wang and H. Jiang, Enhanced adsorption performance of tetracycline in aqueous solutions by methanol-modified biochar, Chem. Eng. J., 2014, 248, 168-174.

74 H. Lu, W. Zhang, Y. Yang, X. Huang, S. Wang and R. Qiu, Relative distribution of Pb2+ sorption mechanisms by sludge-derived biochar, Water Res., 2012, 46, 854-862.

75 C. Lattao, X. Cao, J. Mao, K. Schmidt-Rohr and J. J. Pignatello, Influence of Molecular Structure and Adsorbent Properties on Sorption of Organic Compounds to a Temperature Series of Wood Chars, Environ. Sci. Technol., 2014, 48, 4790-4798.

76 J. J. Pignatello and B. Xing, Mechanisms of Slow Sorption of Organic Chemicals to Natural Particles, Environ. Sci. Technol., 1996, 30, 1-11.

77 H. Qiu, L. Lv, B. Pan, Q. Zhang, W. Zhang and Q. Zhang, Critical review in adsorption kinetic models, J. Zhejiang Univ. A, 2009, 10, 716-724.

78 H. N. Tran, S. J. You, A. Hosseini-Bandegharaei and H. P. Chao, Mistakes and inconsistencies regarding adsorption of contaminants from aqueous solutions: A critical review, Water Res., 2017, 120, 88-116.

79 F. C. Collins and G. E. Kimball, J. Colloid Sci., 1949, 4, 425-437.

80 D. O. Cooney, Adsorption Design for Wastewater Treatment, CRC Press, 1998.

81 C. Tien, Adsorption Calculations and Modeling, Butterworth-Heinemann, 1994.

82 W. Merk, W. Fritz and E. U. Schlünder, Competitive adsorption of two dissolved organics onto activated carbon-III: Adsorption kinetics in fixed beds, Chem. Eng. Sci., 1981, 36, 759-764.

83 G. McKay, Two solutions to adsorption equations for pore diffusion, Water. Air. Soil Pollut., 1991, 60, 117133.

84 S. Lagergren, Zur theorie der sogenannten adsorption gelöster stoffe, K. Sven. Vetenskapsakademiens Handl., 1898, 24, 1-39.

85 Y. S. Ho and G. McKay, Pseudo-second order model for sorption processes, Process Biochem., 1999, 34, 451465.

86 G. Blanchard, M. Maunaye and G. Martin, Removal of heavy metals from waters by means of natural zeolites, Water Res., 1984, 18, 1501-1507.

87 R. kou Xu, S. cheng Xiao, J. hua Yuan and A. zhen Zhao, Adsorption of methyl violet from aqueous solutions by the biochars derived from crop residues, Bioresour. Technol., 2011, 102, 10293-10298.

88 M. Tagliavini, F. Engel, P. G. Weidler, T. Scherer and A. I. Schäfer, Adsorption of steroid micropollutants on polymer-based spherical activated carbon (PBSAC), J. Hazard. Mater., 2017, 337, 126-137.

$89 \mathrm{~J}$. P. Simonin, On the comparison of pseudo-first order and pseudo-second order rate laws in the modeling of adsorption kinetics, Chem. Eng. J., 2016, 300, 254-263.

90 R. P. Schwarzenbach, P. M. Gschwend and D. M. Imboden, Environmental organic chemistry, John Wiley \& Sons, 2005.

$91 \mathrm{R}$. Zhang and P. Somasundaran, Advances in adsorption of surfactants and their mixtures at solid/solution interfaces, Adv. Colloid Interface Sci., 2006, 123-126, 213-229.

92 C. Moreno-Castilla, Adsorption of organic molecules from aqueous solutions on carbon materials, Carbon, 2004, 42, 83-94.

$93 \mathrm{J.} \mathrm{Ni}$, J. J. Pignatello and B. Xing, Adsorption of Aromatic Carboxylate lons to Black Carbon (Biochar) Is Accompanied by Proton Exchange with Water, Environ. Sci. Technol., 2011, 45, 9240-9248. 
94 L. D. Williams, Molecular Interactions and the Behaviors of Biological Macomolecules, 2017. https://ww2.chemistry.gatech.edu/ Iw26/structure/molecular_interactions/mol_int.html

95 G. Kanagaraj and G. N. Rao, Synth. React. Inorganic, Met. Nano-Metal Chem., 1992, 22, 559-574.

96 K. Yang and B. Xing, Adsorption of Organic Compounds by Carbon Nanomaterials in Aqueous Phase: Polanyi Theory and Its Application, Chem. Rev., 2010, 110, 5989-6008.

97 H. Hyung, J. D. Fortner, J. B. Hughes and J.-H. Kim, Natural organic matter stabilizes carbon nanotubes in the aqueous phase, Environ. Sci. Technol., 2007, 41, 179-184.

98 Y. Hu, T. Guo, X. Ye, Q. Li, M. Guo, H. Liu and Z. Wu, Chem. Eng. J., 2013, 228, 392-397.

99 S. Hardinger, Chemisty 14C Thinkbook Twelfth Edition, Hayden-Mcneil Publishing, 2015.

100 M. Kah, G. Sigmund, F. Xiao and T. Hofmann, Sorption of ionizable and ionic organic compounds to biochar, activated carbon and other carbonaceous materials, Water Res., 2017, 124, 673-692.

101 W. Zhang, J. Zheng, P. Zheng and R. Qiu, Atrazine immobilization on sludge derived biochar and the interactive influence of coexisting $\mathrm{Pb}(\mathrm{II})$ or $\mathrm{Cr}(\mathrm{VI})$ ions, Chemosphere, 2015, 134, 438-445.

102 P. Gilli, L. Pretto, V. Bertolasi and G. Gilli, Predicting hydrogen-bond strengths from acid-base molecular properties. The pK(a) slide rule: toward the solution of a long-lasting problem, Acc. Chem. Res., 2009, 42, 33-44.

103 M. Teixidó, J. J. Pignatello, J. L. Beltrán, M. Granados and J. Peccia, Speciation of the ionizable antibiotic sulfamethazine on black carbon (biochar), Environ. Sci. Technol., 2011, 45, 10020-10027.

104 F. Xiao and J. J. Pignatello, Effects of Post-Pyrolysis Air Oxidation of Biomass Chars on Adsorption of Neutral and Ionizable Compounds, Environ. Sci. Technol., 2016, 50, 6276-6283.

105 Y. Tong, L. K. Kimbell, A. Avila, P. J. McNamara and B. K. Mayer, lon Exchange for with Biosolids-Derived Biochar Pretreatment to Remove Micropollutants, Environ. Eng. Sci., 2018, 35.

106 R. R. Domingues, P. F. Trugilho, C. A. Silva, I. C. N. A. De Melo, L. C. A. Melo, Z. M. Magriotis and M. A. Sánchez-Monedero, Properties of biochar derived from wood and high-nutrient biomasses with the aim of agronomic and environmental benefits, PLoS One, 2017, 12.

107 Q. Fang, B. Chen, Y. Lin and Y. Guan, Aromatic and hydrophobic surfaces of wood- derived biochar enhance perchlorate adsorption via hydrogen bonding to oxygen- containing organic groups, Environ. Sci. Technol., 2014, 48, 279-288.

108 L. M. Blaney, S. Cinar and A. K. SenGupta, Hybrid anion exchanger for trace phosphate removal from water and wastewater, Water Res., 2007, 41, 1603-1613.

109 R. Mahmudov and C. P. Huang, Perchlorate removal by activated carbon adsorption, Sep. Purif. Technol., 2010, 70, 329-337.

110 C. A. Hunter and J. K. M. Sanders, The nature of .pi.-.pi. interactions, J. Am. Chem. Soc., 1990, 112, 55255534.

111 M. Sander and J. J. Pignatello, Characterization of Charcoal Adsorption Sites for Aromatic Compounds: Insights Drawn from Single-Solute and Bi-Solute Competitive Experiments, Environ. Sci. Technol., 2005, 39, 1606-1615.

112 J. Lehmann and J. Stephen, Biochar for Environmental Management:Science And Technology, 2009, vol. 1.

$113 \mathrm{H}$. Wijnja, J. J. Pignatello and K. Malekani, Formation of $n-n$ Complexes between Phenanthrene and Model n-Acceptor Humic Subunits, J. Environ. Qual., 2004, 33, 265-275.

114 B. Pan and B. Xing, Adsorption Mechanisms of Organic Chemicals on Carbon Nanotubes, Environ. Sci. Technol., 2008, 42, 9005-9013.

115 J. Toth, Acta Chim. Acad. Sci. Hungaricae, 1971, 69, 311-328.

116 M. Temkin and V. Pyzhev, Acta Physicochim. URSS, 1940, 12, 217-222.

117 L. V. Dubinin, M.M., Radushkevich, Proc. Acad. Sci. Phys. Chem. Sec. USSR, 1947, 55, 331-333.

118 B. Xing, J. J. Pignatello and B. Gigliotti, Competitive Sorption between Atrazine and Other Organic Compounds in Soils and Model Sorbents, Environ. Sci. Technol., 1996, 30, 2432-2440. 
119 S. Rengaraj, C. K. Joo, Y. Kim and J. Yi, Kinetics of removal of chromium from water and electronic process wastewater by ion exchange resins: $1200 \mathrm{H}, 1500 \mathrm{H}$ and IRN97H, J. Hazard. Mater., 2003, 102, 257-275.

120 S. Rengaraj and S.-H. Moon, Kinetics of adsorption of Co(II) removal from water and wastewater by ion exchange resins, Water Res., 2002, 36, 1783-1793.

121 I. C. R. Holford, R. W. M. Wedderburn and G. E. G. Mattingly, A Langmuir two-surface equation as a model for phosphate adsorption by soils, J. Soil Sci., 1974, 25, 242-255.

122 J. K. Syers, M. G. Browman, G. W. Smillie and R. B. Corey, Phosphate Sorption by Soils Evaluated by the Langmuir Adsorption Equation, Soil Sci Soc Am Proc, 1973, 37, 358-363.

123 G. Halsey and H. S. Taylor, The Adsorption of Hydrogen on Tungsten Powders, J. Chem. Phys., 1947, 15, 624630.

124 K. Pyrzynska, A. Stafiej and M. Biesaga, Sorption behavior of acidic herbicides on carbon nanotubes, Microchim. Acta, 2007, 159, 293-298.

125 M. R. Matsumoto, Sep. Sci. Technol., 1993, 28, 2179-2195.

126 Y. S. Ho, Second-order kinetic model for the sorption of cadmium onto tree fern: A comparison of linear and non-linear methods, Water Res., 2006, 40, 119-125.

$127 \mathrm{~S}$. Meenakshi and N. Viswanathan, Identification of selective ion-exchange resin for fluoride sorption, $J$. Colloid Interface Sci., 2007, 308, 438-450.

128 G. Limousin, J.-P. Gaudet, L. Charlet, S. Szenknect, V. Barthès and M. Krimissa, Sorption isotherms: A review on physical bases, modeling and measurement, Appl. Geochemistry, 2007, 22, 249-275.

129 K. K. Shimabuku, J. M. Paige, M. Luna-Aguero and R. S. Summers, Simplified Modeling of Organic Contaminant Adsorption by Activated Carbon and Biochar in the Presence of Dissolved Organic Matter and Other Competing Adsorbates, Environ. Sci. Technol., 2017, 51, 10031-10040.

130 D. Chatzopoulos and A. Varma, Aqueous-phase adsorption and desorption of toluene in activated carbon fixed beds: Experiments and model, Chem. Eng. Sci., 1995, 50, 127-141.

131 K. Y. Foo and B. H. Hameed, Insights into the modeling of adsorption isotherm systems, Chem. Eng. J., 2010, 156, 2-10.

132 A. L. Myers, Thermodynamics of adsorption in porous materials, AIChE J., 2002, 48, 145-160.

133 D. D. Do, D. Nicholson and C. Fan, Development of Equations for Differential and Integral Enthalpy Change of Adsorption for Simulation Studies, Langmuir, 2011, 27, 14290-14299.

134 A. L. Myers and P. A. Monson, Physical adsorption of gases: the case for absolute adsorption as the basis for thermodynamic analysis, Adsorption, 2014, 20, 591-622.

135 V. C. Srivastava, M. M. Swamy, I. D. Mall, B. Prasad and I. M. Mishra, Adsorptive removal of phenol by bagasse fly ash and activated carbon: Equilibrium, kinetics and thermodynamics, Colloids Surfaces $A$ Physicochem. Eng. Asp., 2006, 272, 89-104.

136 G. K. Parshetti, S. Chowdhury and R. Balasubramanian, Hydrothermal conversion of urban food waste to chars for removal of textile dyes from contaminated waters, Bioresour. Technol., 2014, 161, 310-319.

137 W.-Y. Chen, Z.-C. Liu, P.-H. Lin, C.-I. Fang and S. Yamamoto, The hydrophobic interactions of the ionexchanger resin ligands with proteins at high salt concentrations by adsorption isotherms and isothermal titration calorimetry, Sep. Purif. Technol., 2007, 54, 212-219.

138 M. Murialdo, N. P. Stadie, C. C. Ahn and B. Fultz, Observation and Investigation of Increasing Isosteric Heat of Adsorption of Ethane on Zeolite-Templated Carbon, J. Phys. Chem. C, 2015, 119, 944-950.

139 S. E. Weber and S. Talapatra, C. Journet, Z. Zambano and A.D. Mignone, Determination of the binding energy of methane on single-walled carbon nanotube bundles, Phys. Rev. B, 2000, 61, 150-154.

140 J. S. D. Yoo, 2013, 63, 88-92.

141 V. C. Srivastava, I. D. Mall and I. M. Mishra, Adsorption thermodynamics and isosteric heat of adsorption of toxic metal ions onto bagasse fly ash (BFA) and rice husk ash(RHA), Chem. Eng. J., 2007, 132, 267-278. 
142 V. J. Inglezakis and A. A. Zorpas, Heat of adsorption, adsorption energy and activation energy in adsorption and ion exchange systems, Desalin. Water Treat., 2012, 39, 149-157.

143 Y. I. Tarasevich and V. E. Polyakov, in Porous materials in environmentally friendly pocesses, eds. I. Kiricsi, G. Pál-Borbély, J. B. Nagy and H. G. B. T.-S. in S. S. and C. Karge, Elsevier, 1999, vol. 125, pp. 315-320.

144 Y. Feng, D. D. Dionysiou, Y. Wu, H. Zhou, L. Xue, S. He and L. Yang, Adsorption of dyestuff from aqueous solutions through oxalic acid-modified swede rape straw: Adsorption process and disposal methodology of depleted bioadsorbents, Bioresour. Technol., 2013, 138, 191-197.

145 T. Shahwan, D. Akar and A. E. Eroglu, Physicochemical characterization of the retardation of aqueous Cs+ ions by natural kaolinite and clinoptilolite minerals, J. Colloid Interface Sci., 2005, 285, 9-17.

146 P. Senthil Kumar, P. S. A. Fernando, R. T. Ahmed, R. Srinath, M. Priyadharshini, A. M. Vignesh and A. Thanjiappan, Effect of temperature on the adsorption of methylene blue dye onto sulfuric acid-treated orange peel, Chem. Eng. Commun., 2014, 201, 1526-1547.

147 S. K. Milonjic, A consideration of the correct calculation of thermodynamic parameters of adsorption, J. Serbian Chem. Soc., 2007, 72, 1363-1367.

148 Y. Liu, Is the Free Energy Change of Adsorption Correctly Calculated?, J. Chem. Eng. Data, 2009, 54, 19811985.

149 P. S. Ghosal and A. K. Gupta, An insight into thermodynamics of adsorptive removal of fluoride by calcined Ca-Al-(NO 3) layered double hydroxide, RSC Adv., 2015, 5, 105889-105900.

150 Z. Chen, B. Chen, D. Zhou and W. Chen, Bisolute Sorption and Thermodynamic Behavior of Organic Pollutants to Biomass-derived Biochars at Two Pyrolytic Temperatures, Environ. Sci. Technol., 2012, 46, 12476-12483.

151 M. A. Fontecha-Cámara, M. V. López-Ramón, M. A. Álvarez-Merino and C. Moreno- Castilla, Carbon N. Y., 2006, 44, 2335-2338.

152 P. S. and S. Chowdhury, J. Hazard. Mater., 2003, 162, 440.

153 T. S. Anirudhan and P. G. Radhakrishnan, Thermodynamics and kinetics of adsorption of $\mathrm{Cu}(\mathrm{II})$ from aqueous solutions onto a new cation exchanger derived from tamarind fruit shell, J. Chem. Thermodyn., 2008, 40, 702-709.

154 J. F. García-Araya, F. J. Beltrán, P. Álvarez and F. J. Masa, Activated carbon adsorption of some phenolic compounds present in agroindustrial wastewater, Adsorption, 2003, 9, 107-115.

155 Z. Wu, H. Zhong, X. Yuan, H. Wang, L. Wang, X. Chen, G. Zeng and Y. Wu, Adsorptive removal of methylene blue by rhamnolipid-functionalized graphene oxide from wastewater, Water Res., 2014.

156 X. Zhao, W. Ouyang, F. Hao, C. Lin, F. Wang, S. Han and X. Geng, Properties comparison of biochars from corn straw with different pretreatment and sorption behaviour of atrazine, Bioresour. Technol., 2013, 147, 338-344.

157 M. Samaraweera, W. Jolin, D. Vasudevan, A. A. Mackay and J. A. Gascón, Atomistic Prediction of Sorption Free Energies of Cationic Aromatic Amines on Montmorillonite: A Linear Interaction Energy Method, Environ. Sci. Technol. Lett., 2014, 1, 284-289. 